\title{
ANALYTICAL METHOD DEVELOPMENT AND VALIDATION OF CAPMATINIB IN BULK AND TABLET DOSAGE FORM BY RP-HPLC METHOD
}

\author{
Mr. M. Sivaganesh \\ Post graduate student, Department of Pharmaceutical Analysis, Periyar College of \\ Pharmaceutical Sciences, Tiruchirappalli, Tamil Nadu, India. E-Mail Id: \\ sivaganesh2761@gmail.com
}

\section{Mr. M.K.M. Abdul Lathiff}

Associate professor, Department of Pharmaceutical Analysis, Periyar College of

Pharmaceutical Sciences, Tiruchirappalli, Tamil Nadu, India. E-Mail Id: alathiff@gmail.com

\section{Dr. G. Krishnamoorthy}

Vice Principal \& Head, Department of Pharmaceutical Analysis, Periyar College of Pharmaceutical Sciences, Tiruchirappalli, Tamil Nadu, India. E-Mail Id: vkm292011@hotmail.com

\section{Dr. R. Senthamarai,}

Principal, Department of Pharmacognosy, Periyar College of Pharmaceutical Sciences,

Tiruchirappalli. Tamil Nadu, India.E-Mail Id: periyarcps@gmail.com

\section{Miss. S. Ramya}

Post graduate student, Department of Pharmaceutical Analysis, Periyar College of Pharmaceutical Sciences, Tiruchirappalli, Tamil Nadu, India. E-Mail Id: ramyashanthi225@gmail.com

\section{Mr. J. Ijaz Ahamed}

Post graduate student, Department of Pharmaceutical Analysis, Periyar College of Pharmaceutical Sciences, Tiruchirappalli, Tamil Nadu, India. E-Mail, Id: ijazvkr@gmail.com

\section{Corresponding Author:}

Mr. M. Sivaganesh, Post graduate student, Department of Pharmaceutical analysis, Periyar College of Pharmaceutical Sciences, Tiruchirappalli, Tamil Nadu, India. 


\begin{abstract}
An HPLC method was developed and validated for the estimation of Capmatinib in bulk and pharmaceutical dosage form. The chromatographic system was equipped Agilent column $150 \mathrm{~mm} \times 4.6 \mathrm{~mm}$ internal diameter with 5 micron particle size column and UV detector set at $218 \mathrm{~nm}$, in conjunction with a mobile phase of Methanol and phosphate buffer $\mathrm{PH} 5$ in the ratio of (65:35) at a flow rate of $0.5 \mathrm{ml} / \mathrm{min}$. The retention time of capmatinib was found to be 4.3 minute. The separation was performed at ambient temperature. The injection volume was $10 \mu l$. Linearity in concentration range of $10-50 \mu \mathrm{g} \mathrm{mL}$ with regression 0.999. The Percentage recoveries were found in the range of 101.4-101.8\%. The proposed method was validated in accordance with ICH parameters the method is precise, accurate, selective and rapid.
\end{abstract}

Key Words: RP-HPLC, Capmatinib, Validation, and ICH.

\title{
Introduction:
}

Capmatinib, also known as Tabrecta, is a drug used to treat adults with metastatic NonSmall Cell Lung Cancer (NSCLC) whose tumours contain an exon 14 skipping mutation in the MET gene, which codes for the membrane receptor HGFR, as confirmed by an FDA-approved test. Capmatinib and the Foundation One CDx assay as a companion diagnostic for capmatinib were authorised for medical use in the United States in May 2020.

NSCLC (Non-Small Cell Lung Cancer) is a disease in which malignant cancer cells originate in the lung tissues. Non-small cell lung cancer is the most frequent kind of lung cancer, accounting for up to $90 \%$ of all lung carcinomas. When healthy cells become aberrant and expand fast, NSCLC develops. One of the dangers of this type of cancer is that the cancer cells are likely to travel from the lungs to other organs and body parts. Cancer metastasis is comprised of a variety of events, with MET exon 14 skipping being recognised as a crucial step in carcinoma metastasis. MET exon 14 skipping mutations are detected in 3-4 percent of lung cancer patients.

\section{Structure:}

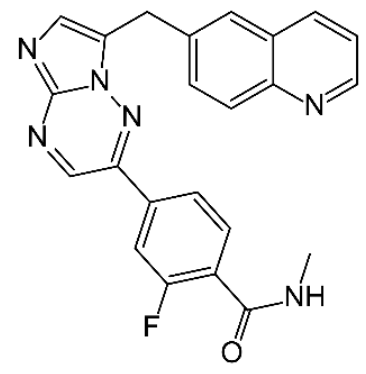

\section{IUPAC Name:}

2-fluoro- $N$-methyl-4-[7-(quinolin-6-ylmethyl)imidazo[1,2-b][1,2,4]triazin-2yl]benzamide.

\section{Mechanism of Action:}

Many malignancies, including non-small cell lung cancer, have been shown to have abnormal c-Met activity (NSCLC). Mutations that cause MET exon 14 to be skipped result in 
the creation of a mutant c-Met protein that lacks a regulatory domain; these mutant proteins have a diminished ability to negatively regulate, resulting in a pathological increase in their downstream activity.

Capmatinib blocks c-Met-mediated phosphorylation of downstream signalling proteins, as well as cell proliferation, by inhibiting the phosphorylation of both wild-type and mutant versions of c-Met caused by the binding of its endogenous ligand, hepatocyte growth factor.

\section{Materials and Methods:}

\section{Apparatus:}

SIMADZU Prominence HPLC iLC2030 Plus

\section{Materials and reagent:}

All the chemicals used were of analytical and HPLC grade. An analytically pure sample for capmatinib was procured as a gift sample from the Nebulae Hi Tech Laboratory, Chennai -116

\section{Solvents:}

Methanol, phosphate buffer of HPLC grade and Milli Q water were used in analysis.

\section{Preparation of Phosphate buffer}

7.0 grams of Potassium dihydrogen Phosphate was weighed accurately and transferred into a $1000 \mathrm{ml}$ beaker, dissolved and diluted to $1000 \mathrm{ml}$ with HPLC water. The $\mathrm{pH}$ was adjusted to 3.0 with Ortho phosphoric acid.

\section{Preparation of mobile phase}

Phosphate buffer $350 \mathrm{ml}(35 \%)$ and $650 \mathrm{ml}$ of Methanol HPLC (65\%) was measured and mix well. Then the solution was degassing in ultrasonic water bath for 5 minutes. Filter through $0.45 \mu$ filter under vacuum filtration.

\section{Preparation of Standard stock solution}

About $10 \mathrm{mg}$ Capmantinib was accurately weighed and transfer of into a $10 \mathrm{ml}$ volumetric flask add about $7 \mathrm{ml}$ of mobile phase and sonicate to dissolve it completely and make volume up to the mark with the mobile phase. The solution was observed to contain $1000 \mu \mathrm{g} / \mathrm{ml}$.

\section{SYSTEM SUITABILITY}

\begin{tabular}{|c|c|}
\hline Parameter & Capmantinib \\
\hline Tailing factor & 1.6 \\
\hline No. of Theoretical plates & 2514.6 \\
\hline Retention time & 4.349 \\
\hline
\end{tabular}




\section{Preparation of Sample solution}

10 tablets of Capmantinib were weighed and calculate the average weight. Accurately weigh and transfer the sample equivalent to $10 \mathrm{mg}$ of Capmantinib into a $10 \mathrm{ml}$ volumetric flask. Add about $7 \mathrm{ml}$ of mobile phase and sonicate to dissolve it completely and make volume up to the mark with the mobile phase. Mix well and filter through $0.45 \mu \mathrm{m}$ filter.

\section{Linearity:}

In this method, the aliquots of stock solution of Capmantinib $(0.1-0.5 \mathrm{ml}$ of $1000 \mu \mathrm{g} / \mathrm{ml})$ were transferred into five $10 \mathrm{ml}$ volumetric flask and make up to the mark with mobile phase. A solution contains 10,20,30, 40 and $50 \mu \mathrm{g} / \mathrm{ml}$ of Capmantinib in mobile phase. The solutions were injected and the chromatograms were recorded at $218 \mathrm{~nm}$. It was found that the above concentration range was linear with the concentration range of $10-50 \mu \mathrm{g} / \mathrm{ml}$. The peak area was plotted against concentration and the calibration curve was constructed.

\section{Quantification of Formulation}

$20 \mu \mathrm{l}$ of the standard, sample solution $(30 \mu \mathrm{g} / \mathrm{ml})$ was injected into the chromatographic system. Chromatogram was recorded and the peak area was measured. Then calculate the \% purity by using the formulae.

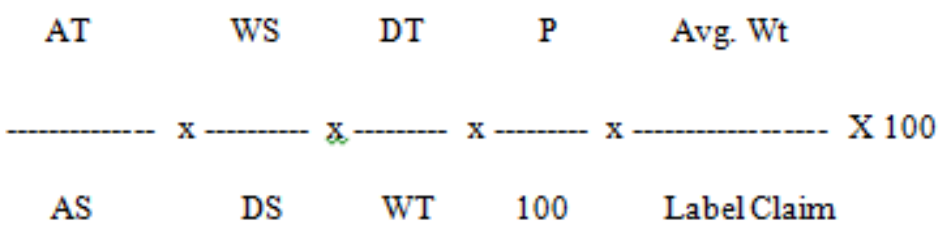

Where,

AT $=$ Peak Area of Capmantinib obtained with test preparation

AS $=$ Peak Area of Capmantinib obtained with standard preparation

WS $=$ Weight of working standard taken in $\mathrm{mg}$

WT $=$ Weight of sample taken in $\mathrm{mg}$

DS $=$ Dilution of Standard solution

DT $=$ Dilution of sample solution

$\mathrm{P} \quad=$ Percentage purity of working standard

\section{Recovery study:}

Equivalent to $10 \mathrm{mg}$ of Capmatinib tablet powder was accurately weighed and transfer into a three separate $10 \mathrm{ml}$ volumetric flask. Then $5 \mathrm{mg}, 10 \mathrm{mg}$ and $15 \mathrm{mg}(50 \%, 100 \%, 150 \%)$ of standard were accurately weighed and added. $7 \mathrm{ml}$ of methanol was added and sonicate to dissolve it completely. Then it was made volume up to the mark with the same solvent. $0.3 \mathrm{ml}$ was pipette out from each flask and transferred to separate $10 \mathrm{ml}$ volumetric flask. Then the solution was made volume up to the mark with the same solvent. $20 \mu 1$ solution was injected in to the chromatographic system. Percentage recovery was calculated by using peak area. 


\section{Precision and Intermediate Precision}

Pipette out $0.3 \mathrm{ml}$ of the stock solution into a $10 \mathrm{ml}$ volumetric flask and dilute up to the mark with mobile phase. Mix well and filter through $0.45 \mu \mathrm{m}$ filter. The solution was observed to contain $30 \mu \mathrm{g} / \mathrm{ml}$. The solution was injected for five times and the chromatogram was recorded. Peak area was used to calculate the \%RSD value.

\section{Robustness}

As part of the robustness, deliberate change in the flow rate, mobile phase composition was made to evaluate the impact of the method.

a. Flow rate was varied at $0.5-0.7 \mathrm{ml} / \mathrm{min}$

b. Organic composition in the mobile phase was varied $60 \%-50 \%$.

\section{Results \&Discussion}

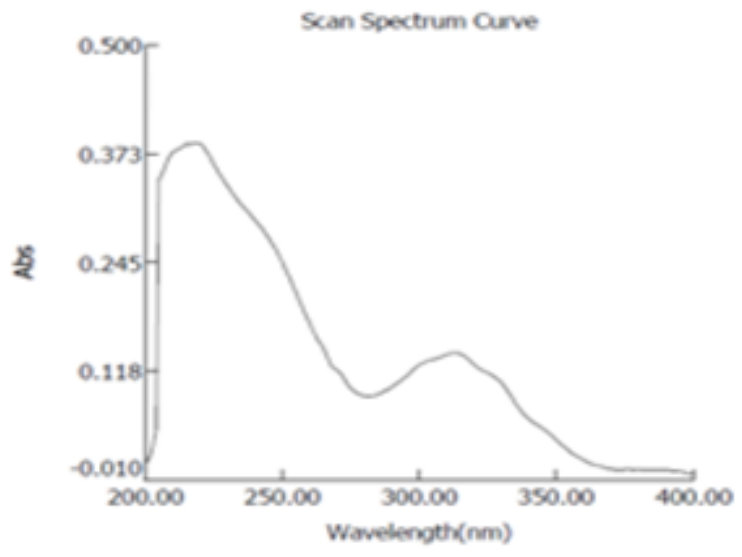

UV Spectrum of Capmantinib in Methanol: Phosphate buffer pH 3.0 (55:45\% v/v)

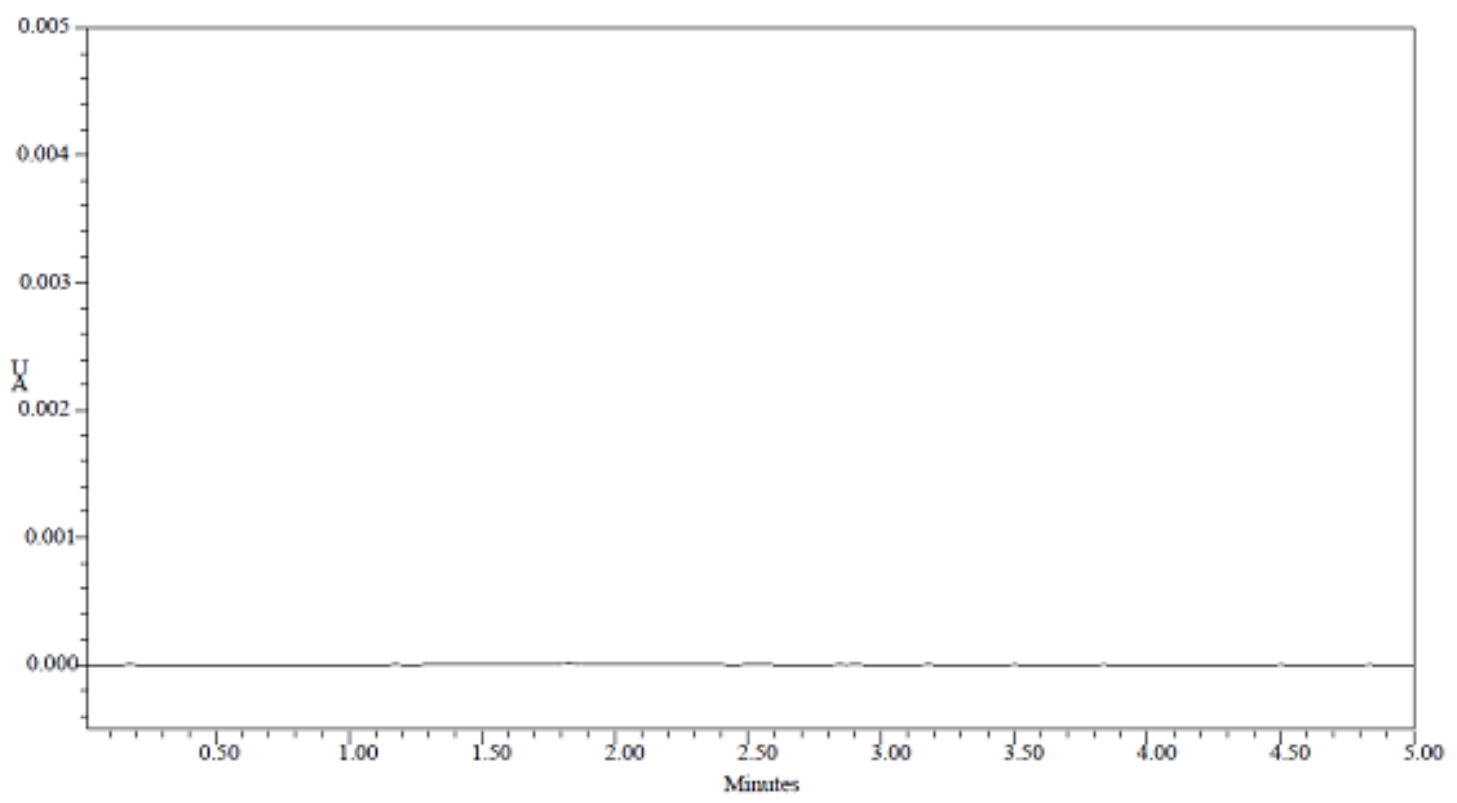

Blank 


\begin{tabular}{|c|c|}
\hline & $\begin{array}{c}\text { Baseline Noise } \\
(\mathrm{mV})\end{array}$ \\
\hline 1 & 0.052 \\
\hline
\end{tabular}

\section{Initial separation conditions}

Mode of operation

Stationary phase

Mobile phase

Ratio

Detection wavelength

Flow rate

Temperature

Sample volume
: $\quad$ Isocratic

: $\quad \mathrm{C}_{18}$ Column ( $150 \mathrm{~mm} \times \mathrm{m} 4.6 \mathrm{~mm}$ i.d., $\left.5 \mu\right)$

: $\quad$ Methanol : Phosphate buffer $\mathrm{pH} 2.5$

: $\quad 50: 50 \% \mathrm{v} / \mathrm{v}$

: $\quad 218 \mathrm{~nm}$

: $\quad 0.5 \mathrm{ml} / \mathrm{min}$

: Ambient

: $\quad 20 \mu 1$

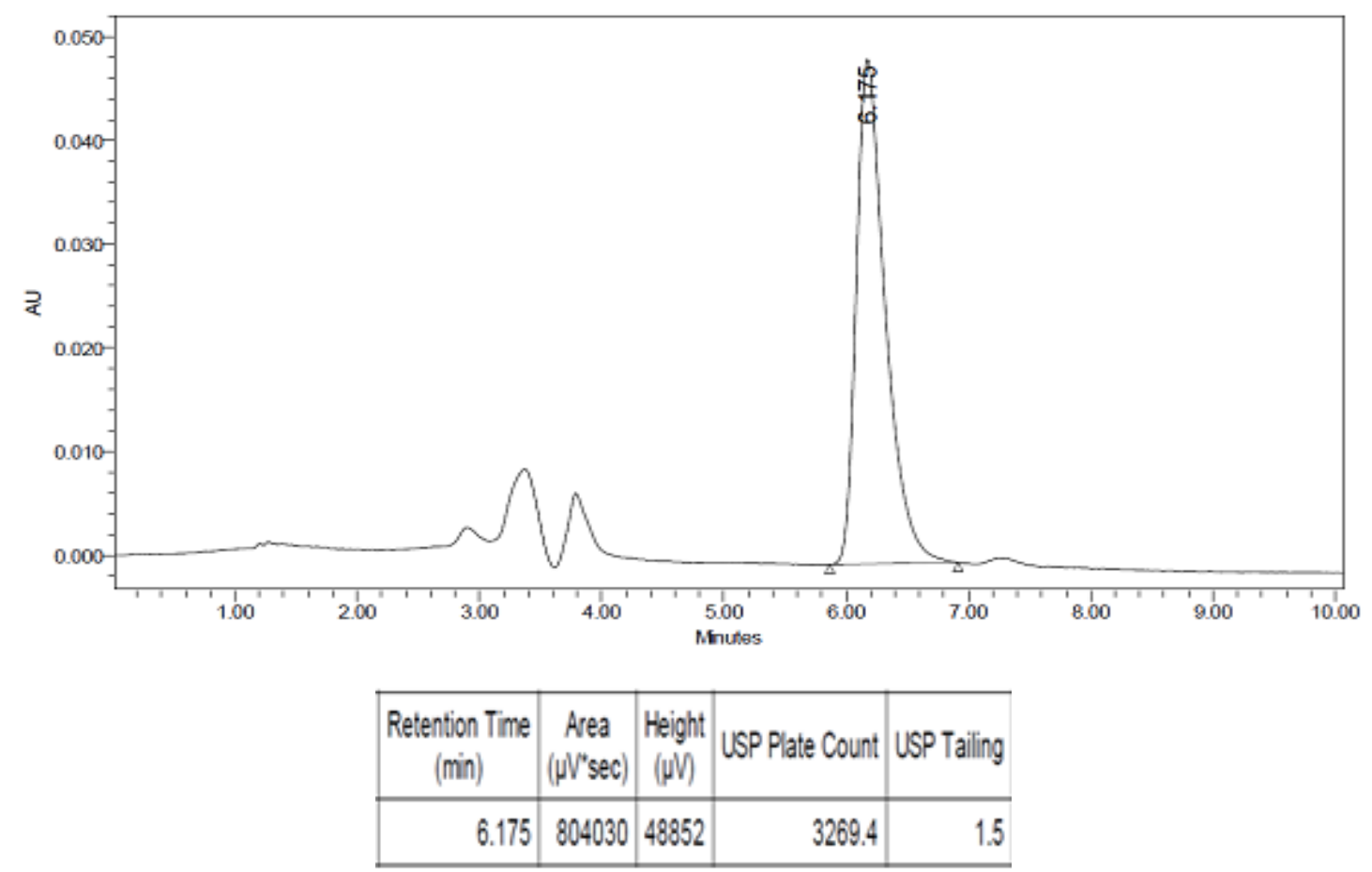

Trial-1 Methanol: Phosphate Buffer pH 2.5 (55:45\% V/V) 


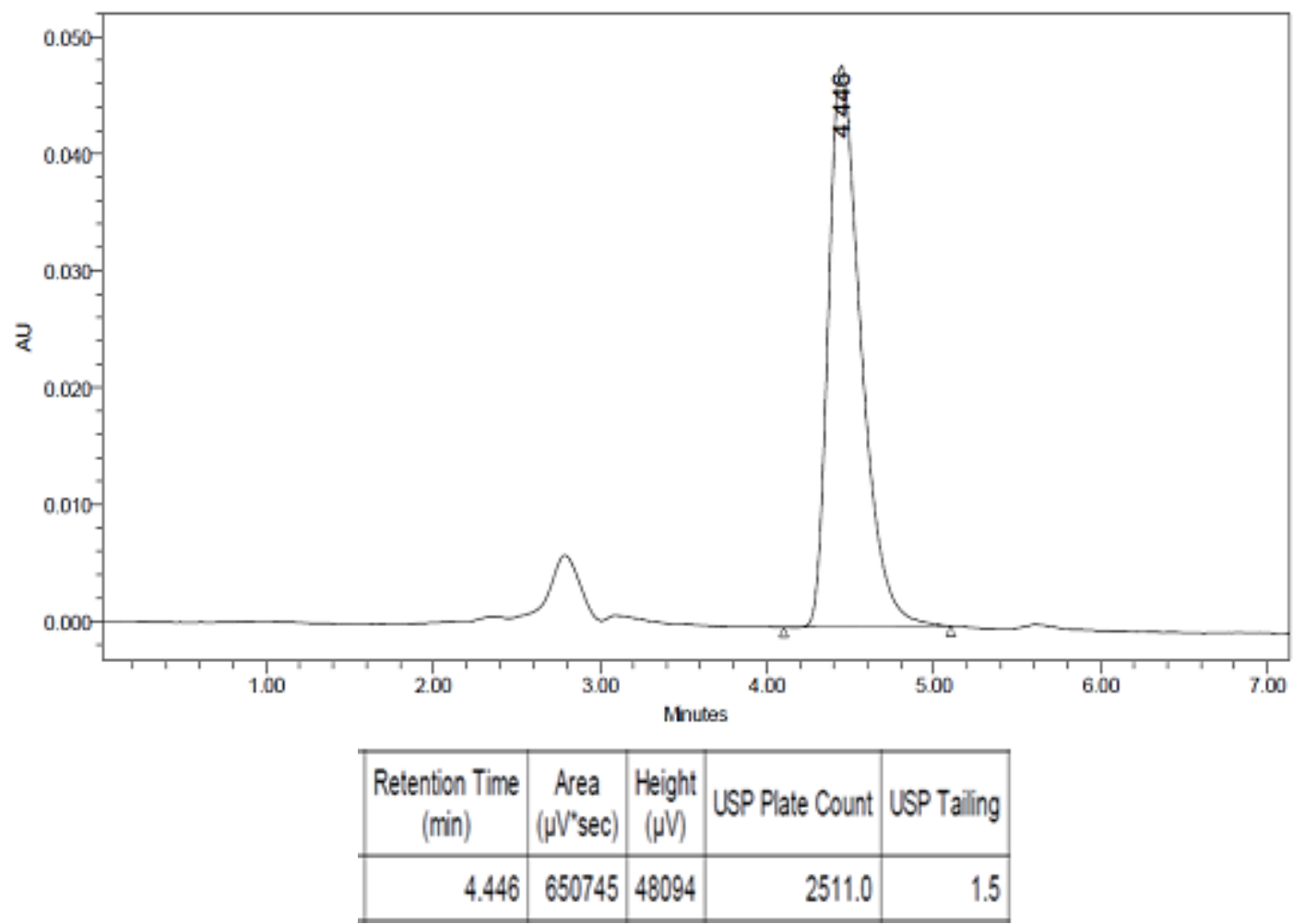

Trial-2 Methanol : Phosphate Buffer pH 3.0 (45:55\% V/V)

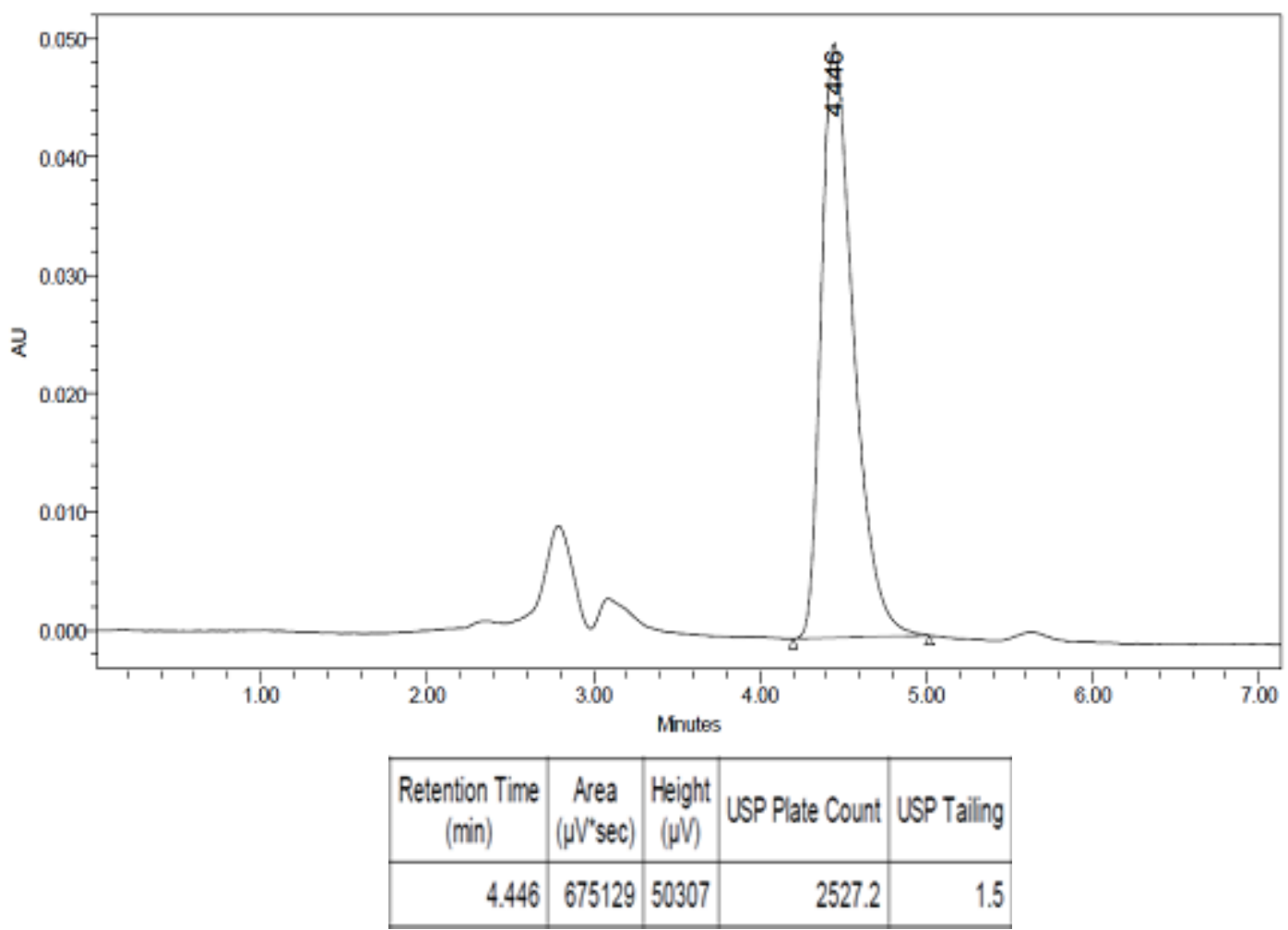

Trial-3 Methanol: Phosphate Buffer pH 3.0 (50:50\% V/V) 


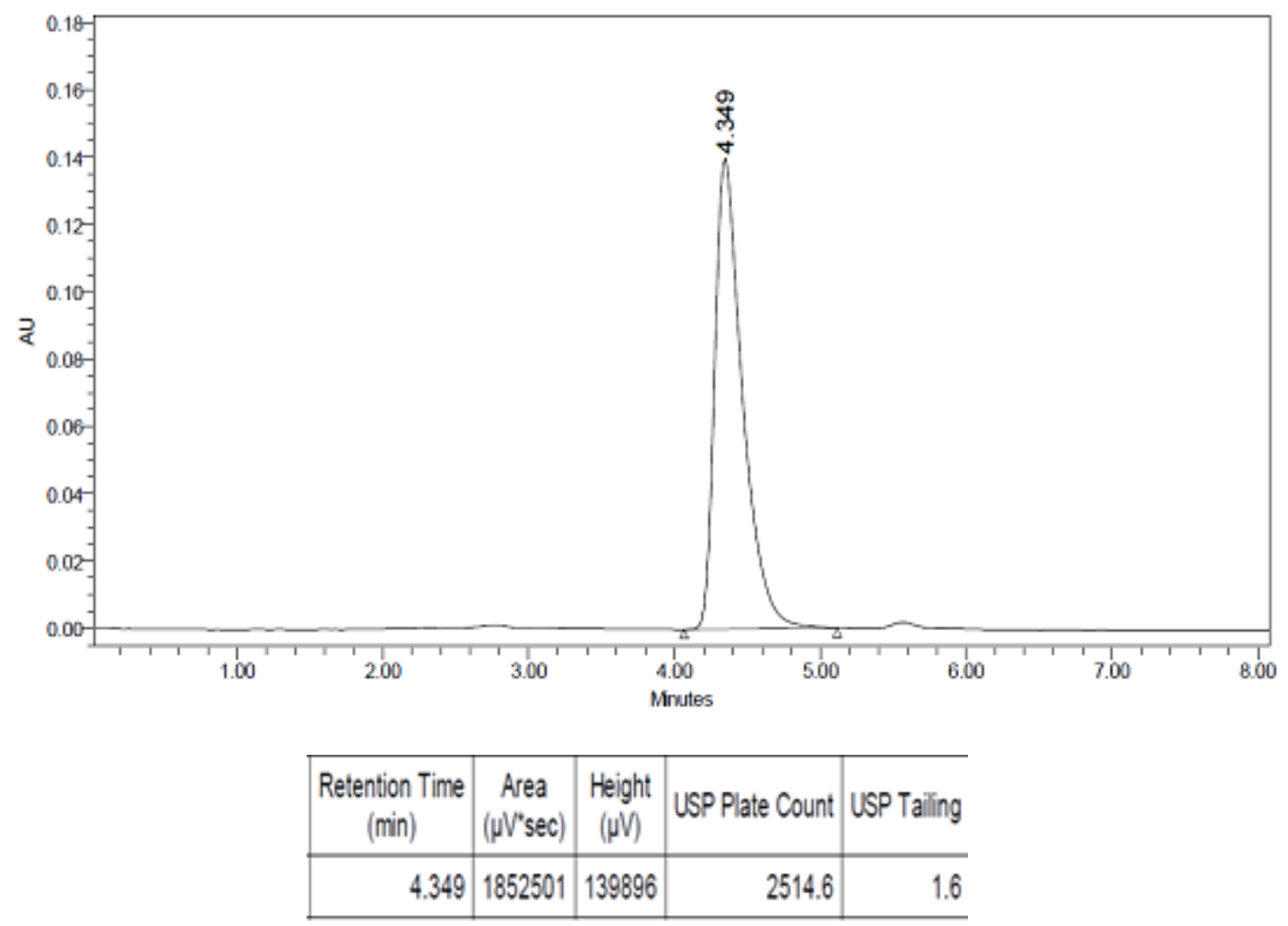

Methanol: Phosphate Buffer pH 3.0 (65:35\% V/V)

\section{Optimized Chromatographic Conditions}

Mode of operation

Stationary phase

Mobile phase

Ratio

Detection wavelength

Flow rate

Temperature

Sample volume
: $\quad$ Isocratic

: $\quad \mathrm{C}_{18}$ Column ( $150 \mathrm{~mm}$ x $4.6 \mathrm{~mm}$ i.d., $5 \mu$ )

: $\quad$ Methanol : Phosphate buffer $\mathrm{pH} 3.0$

: $\quad 65: 35 \% \mathrm{v} / \mathrm{v}$

: $\quad 218 \mathrm{~nm}$

: $\quad 0.6 \mathrm{ml} / \mathrm{min}$

: Ambient

: $\quad 20 \mu 1$ 


\section{Linearity:}

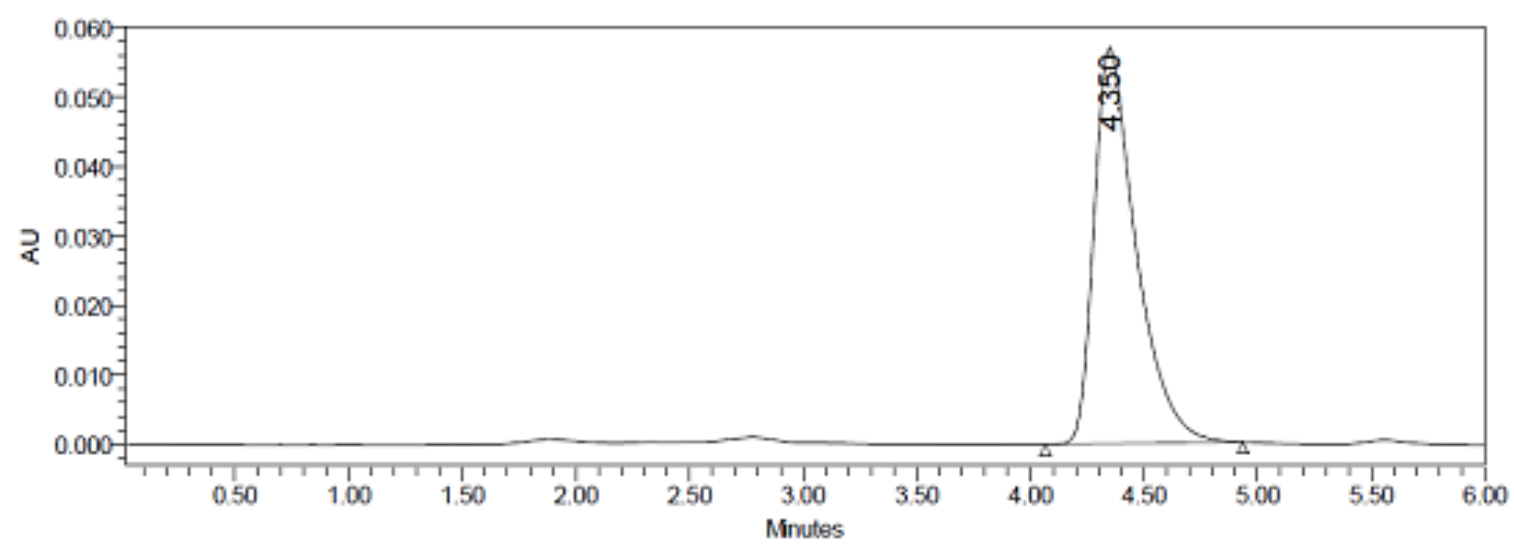

Linearity Chromatogram of $10 \mu \mathrm{g} / \mathrm{ml}$

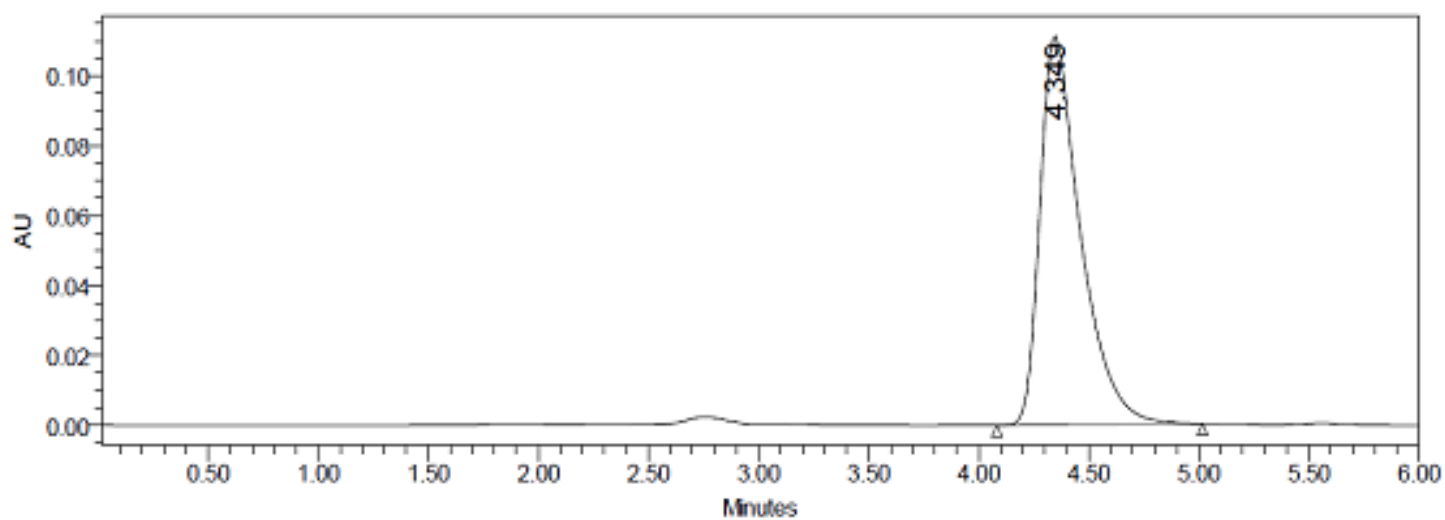

Linearity Chromatogram of $20 \mu \mathrm{g} / \mathrm{ml}$

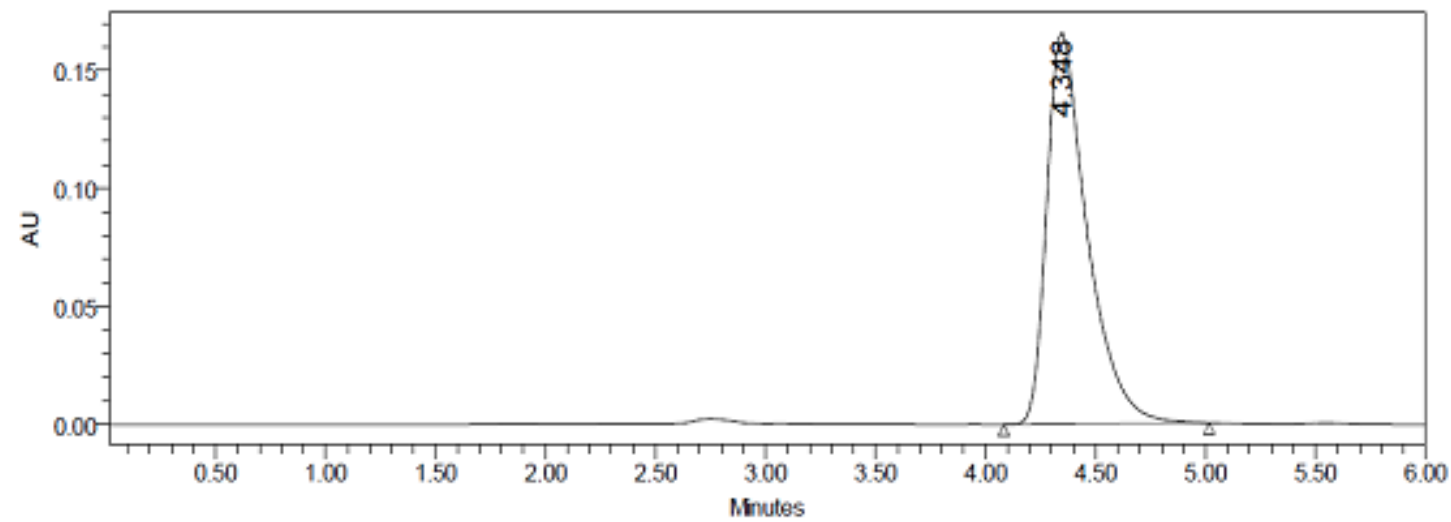

Linearity Chromatogram of $30 \mu \mathrm{g} / \mathrm{ml}$ 


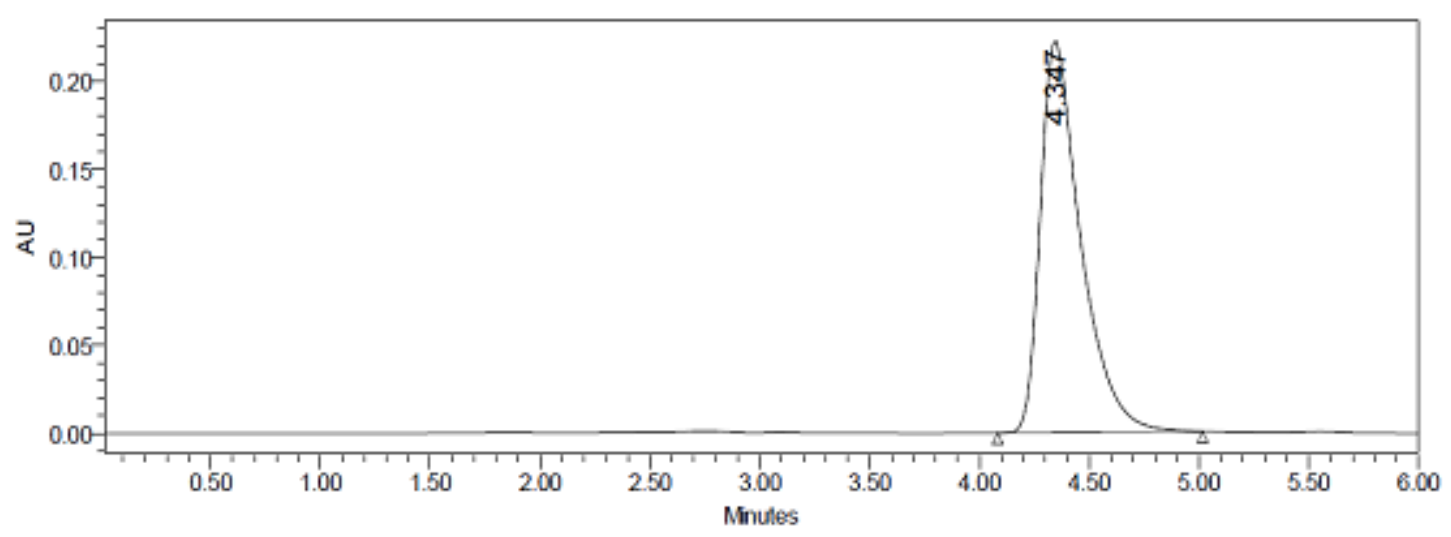

Linearity Chromatogram of $40 \mu \mathrm{g} / \mathrm{ml}$

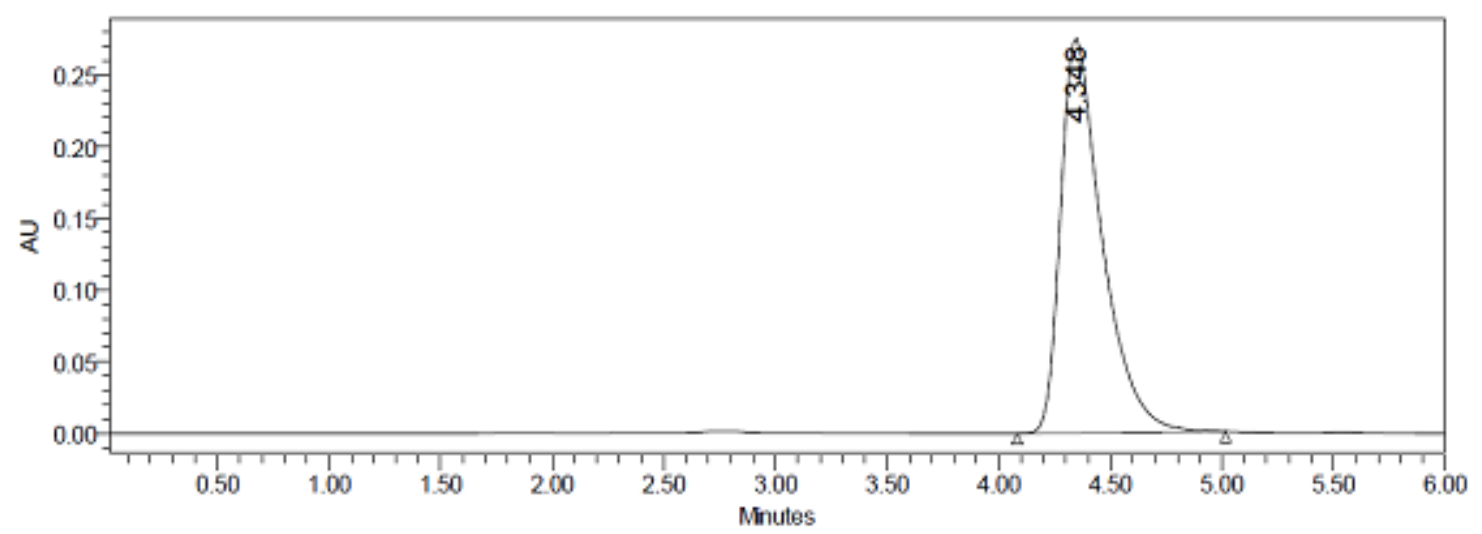

Linearity Chromatogram of $50 \mu \mathrm{g} / \mathrm{ml}$

\begin{tabular}{|c|c|c|}
\hline RT & Area & $\begin{array}{c}\text { Height } \\
(\mu \mathrm{V})\end{array}$ \\
\hline 4.350 & 732615 & 57164 \\
\hline 4.349 & 1425124 & 111274 \\
\hline 4.348 & 2122337 & 165927 \\
\hline 4.347 & 2844280 & 222559 \\
\hline 4.348 & 3551477 & 275507 \\
\hline
\end{tabular}

Linearity Study Data 


\begin{tabular}{|c|c|c|c|c|c|c|c|}
\hline S.No & $\begin{array}{c}\text { Concentration } \\
\mu \mathrm{g} / \mathrm{ml}\end{array}$ & $\begin{array}{c}\text { Average } \\
\text { Peak } \\
\text { Area }\end{array}$ & $\begin{array}{c}\text { Correlation } \\
\text { Coefficient }\end{array}$ & LOD & LOQ & Slope & Intercept \\
\hline 1 & 10 & 732615 & \multirow{5}{*}{0.999} & \multirow{5}{*}{$\begin{array}{l}0.027 \\
\mu \mathrm{g} / \mathrm{ml}\end{array}$} & \multirow{5}{*}{$\begin{array}{c}0.09 \\
\mu \mathrm{g} / \mathrm{ml}\end{array}$} & \multirow{5}{*}{70827} & \multirow{5}{*}{8620} \\
\hline 2 & 20 & 1425124 & & & & & \\
\hline 3 & 30 & 2122337 & & & & & \\
\hline 4 & 40 & 2844280 & & & & & \\
\hline 5 & 50 & 3551477 & & & & & \\
\hline
\end{tabular}

\section{Calibration curve for Capmantinib}

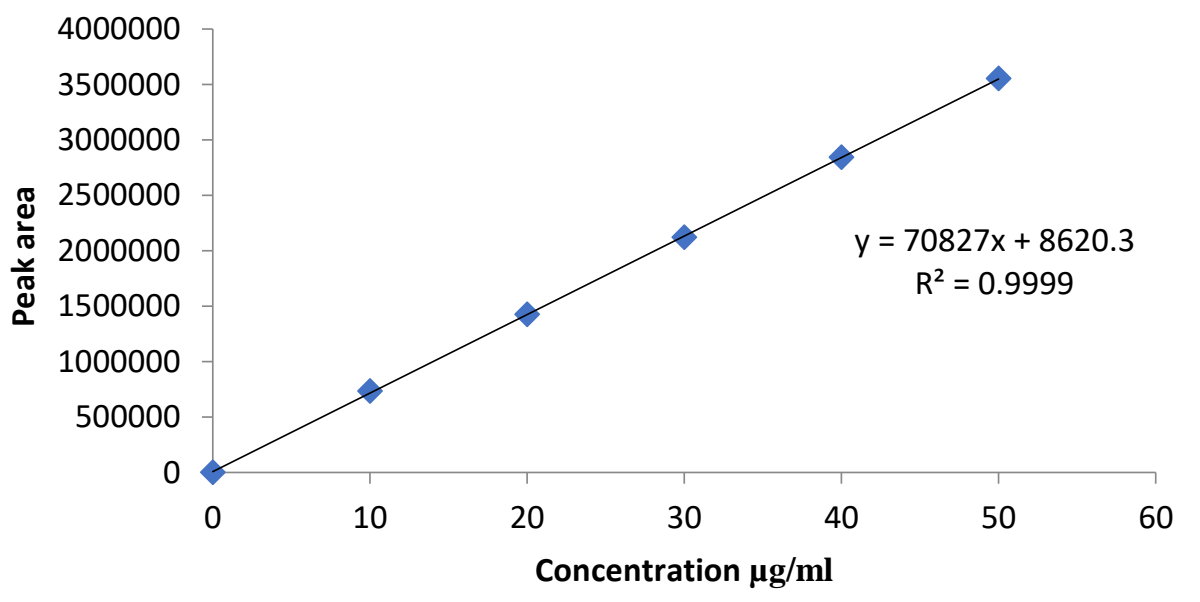

Calibration Curve

\section{LOD \& LOQ}

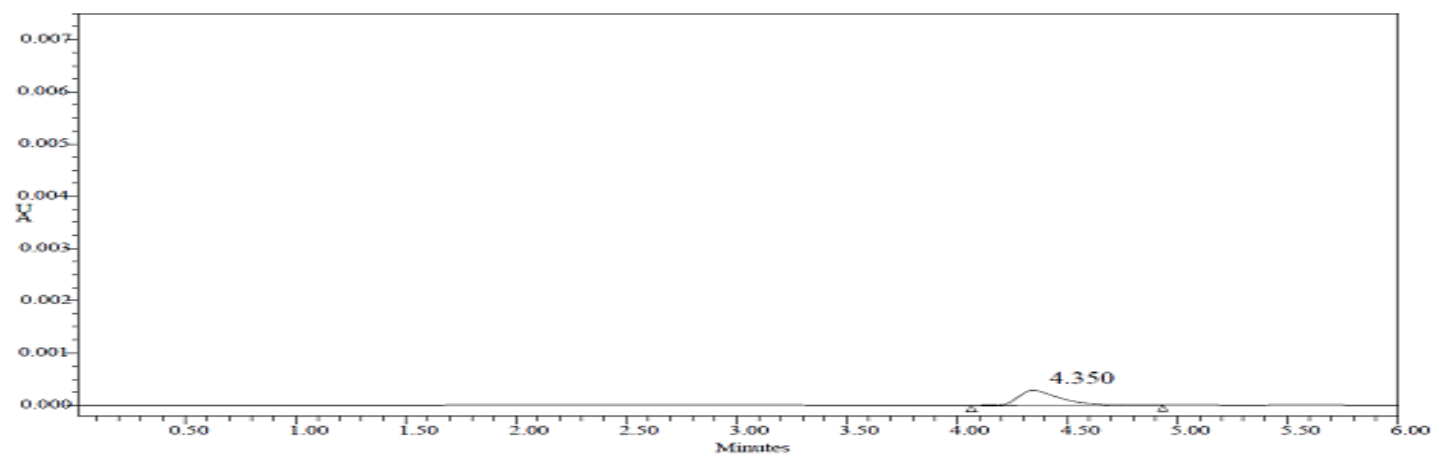




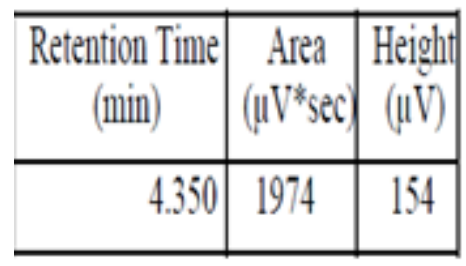

Chromatogram for LOD

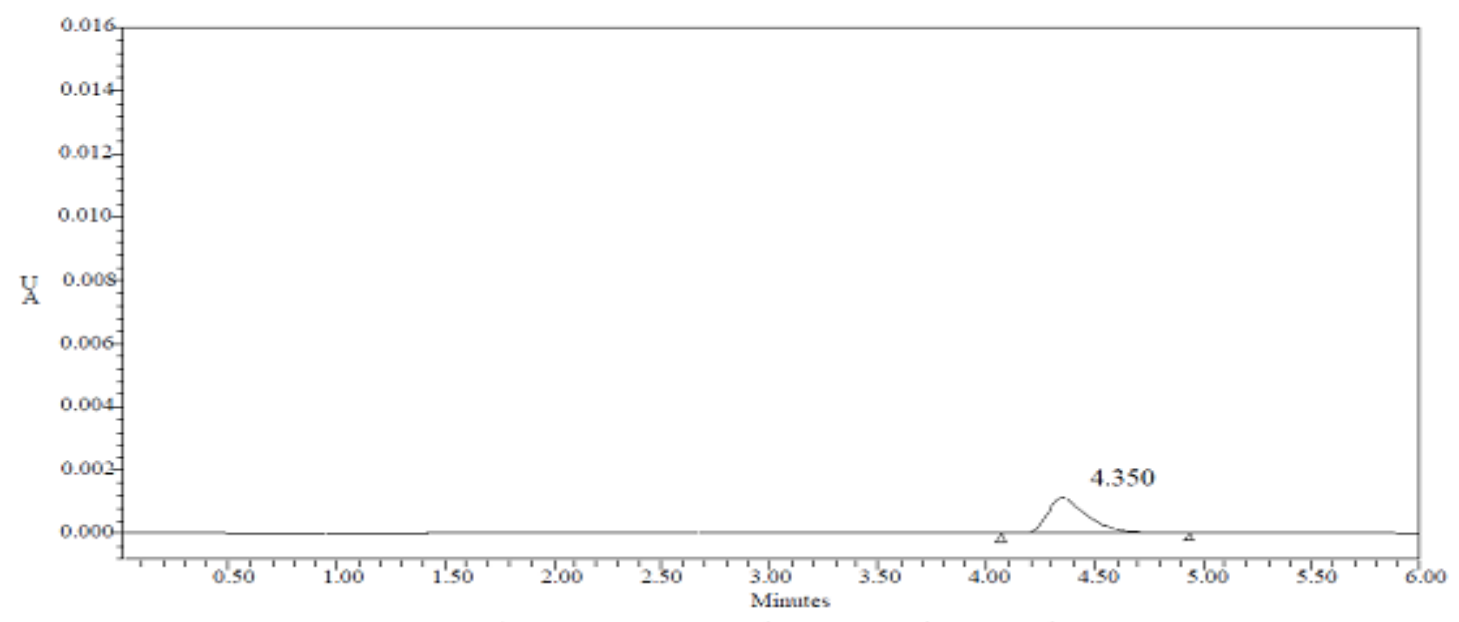

\begin{tabular}{|c|c|c|}
\hline $\begin{array}{c}\text { Retention Time } \\
(\mathrm{min})\end{array}$ & $\begin{array}{c}\text { Area } \\
\left(\mu \mathrm{V}^{*} \mathrm{sec}\right)\end{array}$ & $\begin{array}{c}\text { Height } \\
(\mu \mathrm{V})\end{array}$ \\
\hline 4.350 & 6613 & 516 \\
\hline
\end{tabular}

Chromatogram for LOQ of Capmantinib by RP-HPLC Method Quantification of Formulation

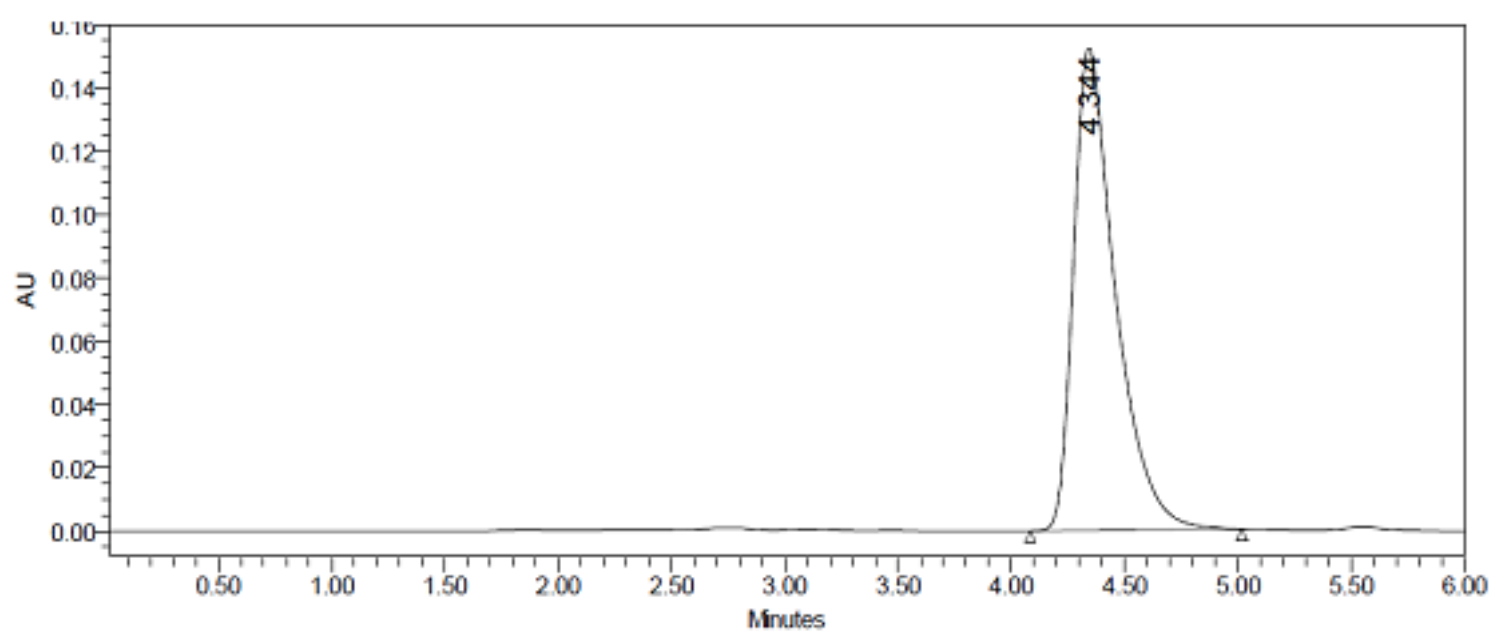




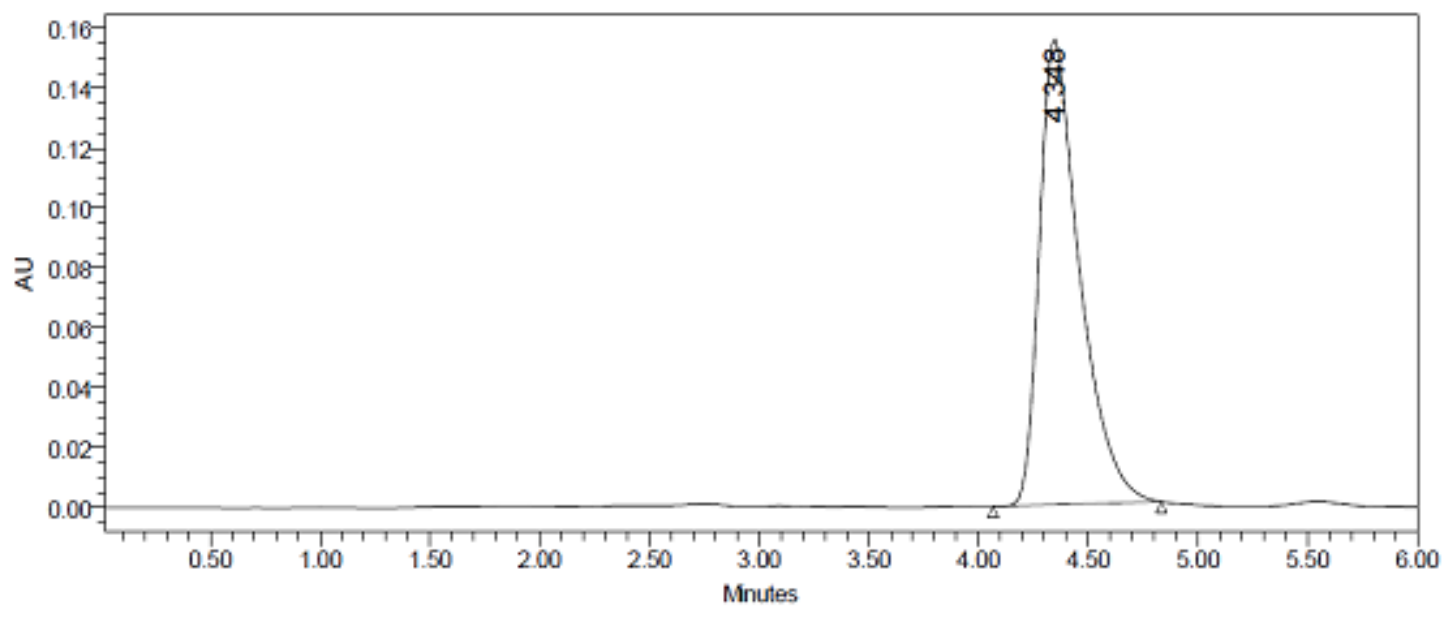

\begin{tabular}{|c|r|c|r|r|}
\hline RT & Injection & Area & USP Plate Count & USP Tailing \\
\hline 4.344 & 1 & 1963547 & 2686.9 & 1.6 \\
\hline 4.348 & 2 & 1985850 & 2664.2 & 1.6 \\
\hline
\end{tabular}

Chromatogram for Assay of Capmantinib Std
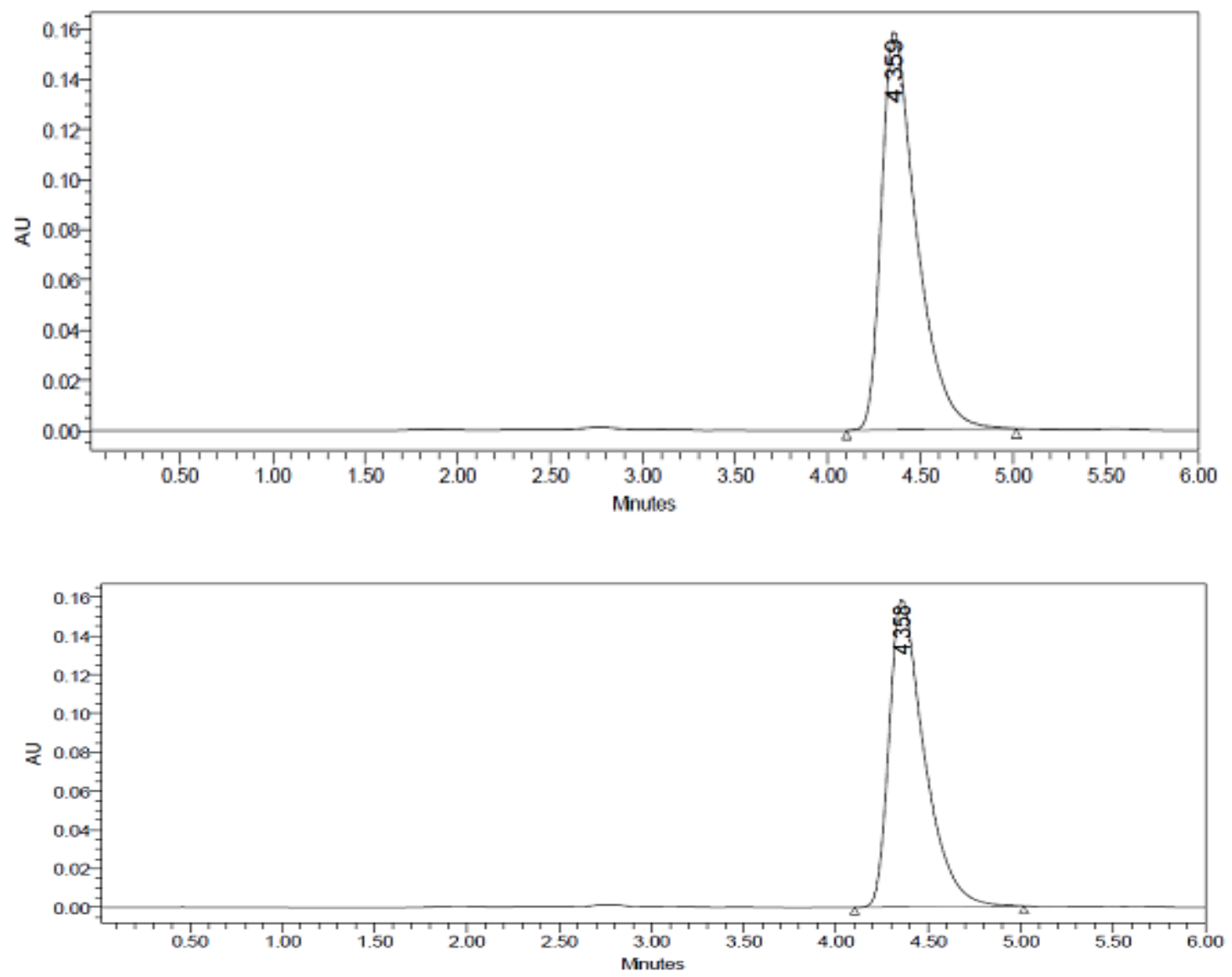


\begin{tabular}{|c|r|c|}
\hline RT & Injection & Area \\
\hline 4.359 & 1 & 2097588 \\
\hline 4.358 & 2 & 2097186 \\
\hline
\end{tabular}

Chromatogram for Assay of Capmantinib Sample

Quantification of formulation- Data

\begin{tabular}{|l|l|l|l|l|l|l|}
\hline S.No & $\begin{array}{l}\text { Standard } \\
\text { Peak Area }\end{array}$ & $\begin{array}{l}\text { Sample } \\
\text { Peak area }\end{array}$ & $\begin{array}{l}\text { Percentage } \\
\text { purity (\%) }\end{array}$ & $\begin{array}{l}\text { Average } \\
\text { Percentage (\%) }\end{array}$ & SD & \% RSD \\
\hline 1 & 1963547 & 2097588 & 101.32 & 100.91 & 0.5798 & 0.5745 \\
2 & 1985850 & 2097186 & 100.50 & & & \\
\hline
\end{tabular}

\section{Recovery study:}
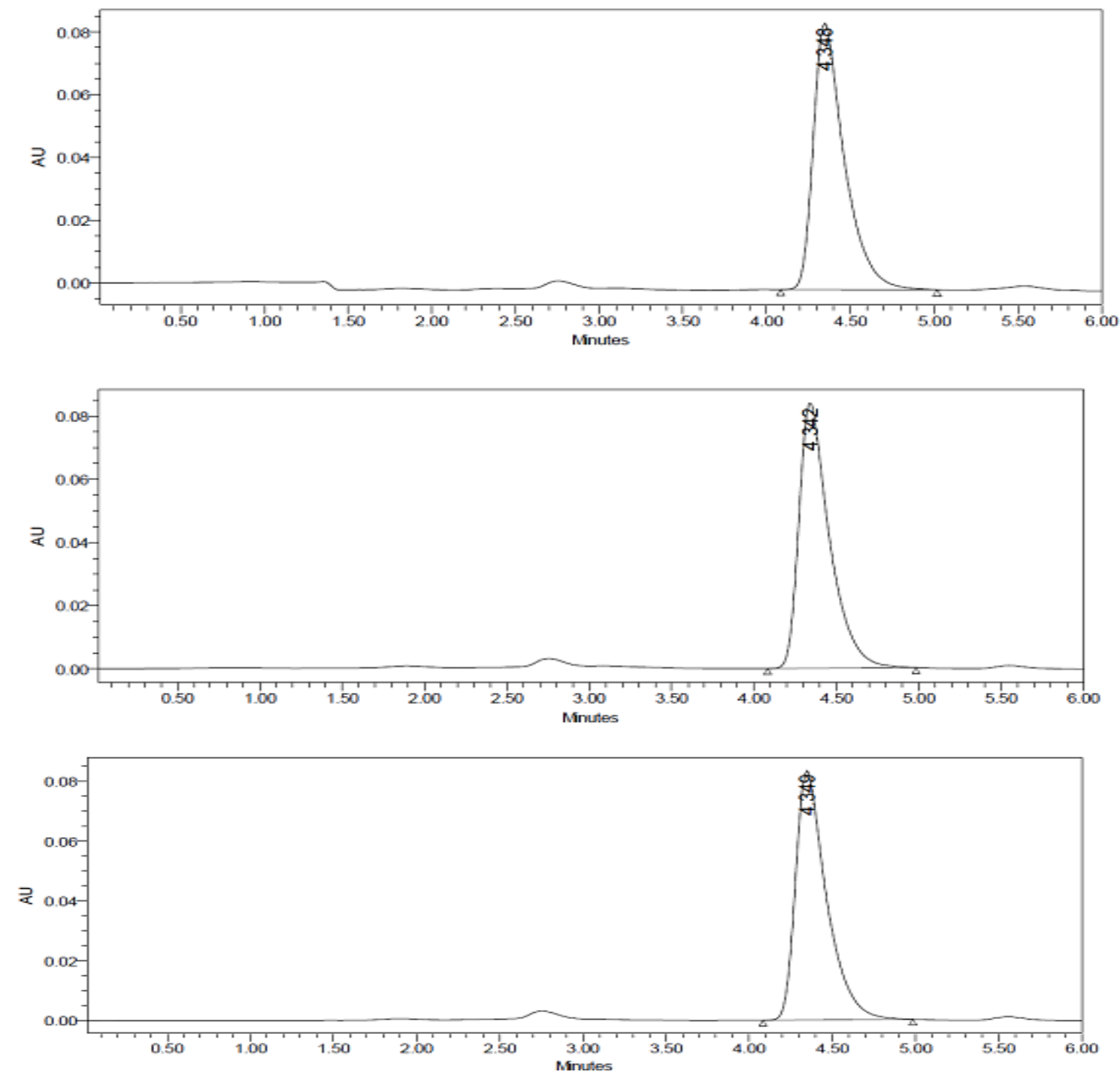


\begin{tabular}{|c|r|c|}
\hline RT & Injection & Area \\
\hline 4.348 & 1 & 1093945 \\
\hline 4.342 & 2 & 1080744 \\
\hline 4.349 & 3 & 1077761 \\
\hline
\end{tabular}

Recovery $\mathbf{- 5 0 \%}$
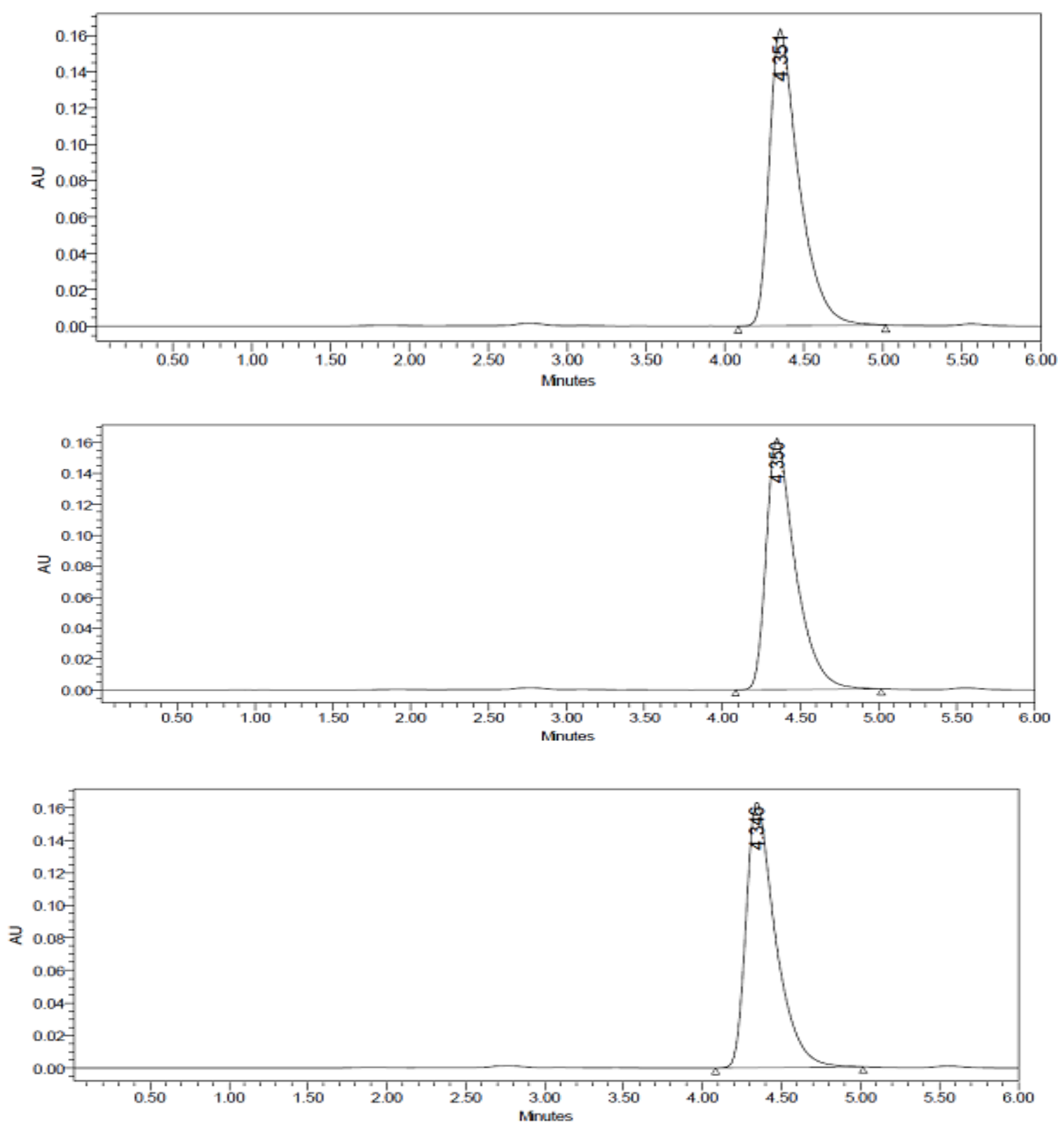

\begin{tabular}{|c|r|c|}
\hline RT & Injection & Area \\
\hline 4.351 & 1 & 2122514 \\
\hline 4.350 & 2 & 2103477 \\
\hline 4.346 & 3 & 2114088 \\
\hline
\end{tabular}

Recovery - 100\% 

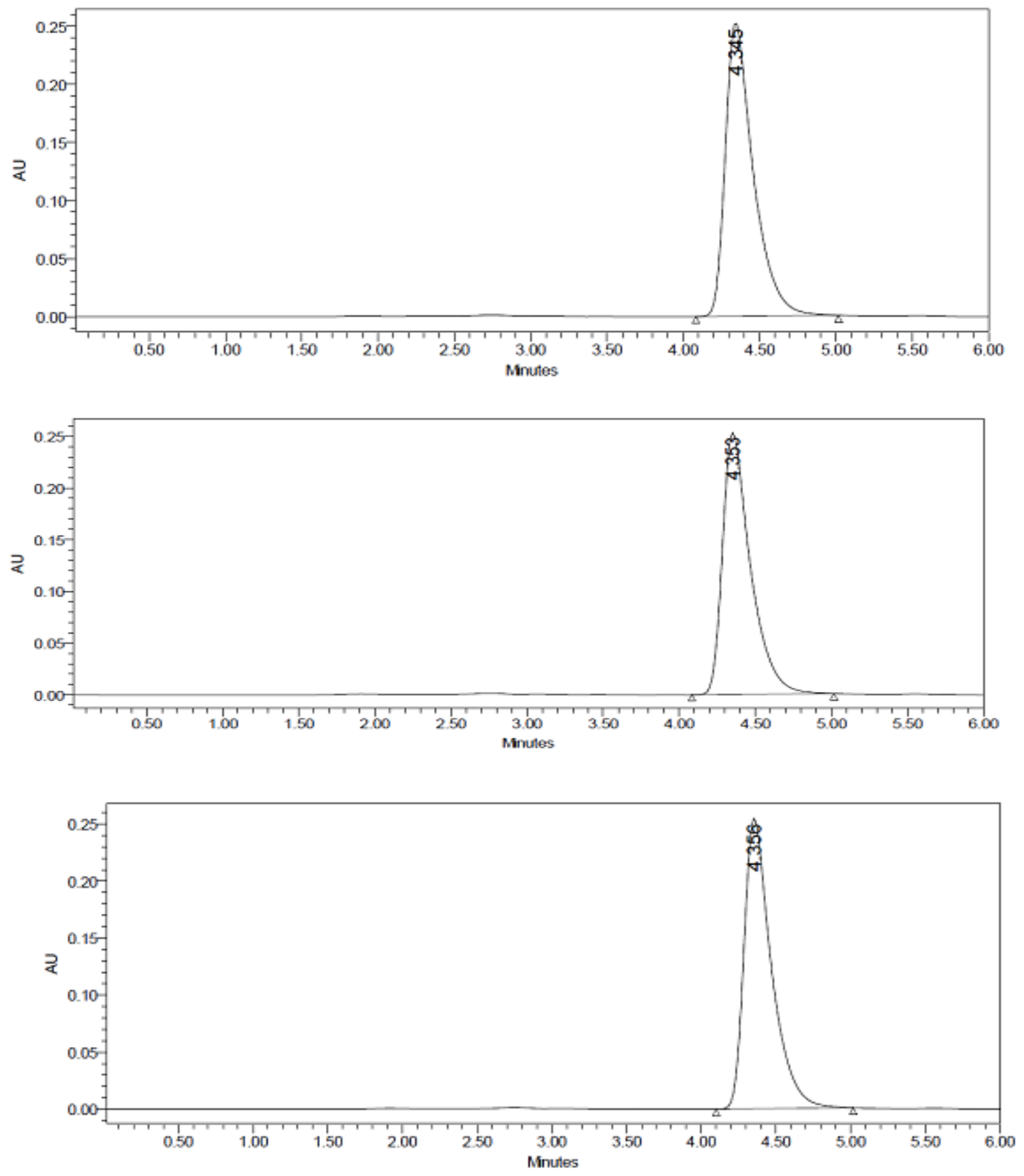

\begin{tabular}{|c|r|c|}
\hline RT & Injection & Area \\
\hline 4.345 & 1 & 3221451 \\
\hline 4.353 & 2 & 3227346 \\
\hline 4.356 & 3 & 3231256 \\
\hline
\end{tabular}

Recovery $\mathbf{- 1 5 0 \%}$ 
Recovery Study data

\begin{tabular}{|c|c|c|c|c|c|c|c|}
\hline $\begin{array}{c}\% \\
\text { Concentration }\end{array}$ & $\begin{array}{c}\text { Average } \\
\text { Area }\end{array}$ & $\begin{array}{c}\text { Amount } \\
\text { Added } \\
(\mathbf{m g})\end{array}$ & $\begin{array}{c}\text { Amount } \\
\text { Found } \\
(\mathbf{m g})\end{array}$ & $\begin{array}{c}\% \\
\text { Recovery }\end{array}$ & $\begin{array}{c}\text { Mean } \\
\text { Recovery }\end{array}$ & SD & $\begin{array}{c}\% \\
\text { RSD }\end{array}$ \\
\hline $50 \%$ & 1084150 & 5.36 & 5.46 & $101.8 \%$ & & & \\
\hline $100 \%$ & 2113360 & 10.5 & 10.6 & $101.4 \%$ & $101.6 \%$ & 0.2 & 0.19 \\
\hline $150 \%$ & 3226684 & 16.0 & 16.2 & $101.6 \%$ & & & \\
\hline
\end{tabular}

$\%$ RSD value less than $2 \%$ was found

\section{Precision and Intermediate Precision}

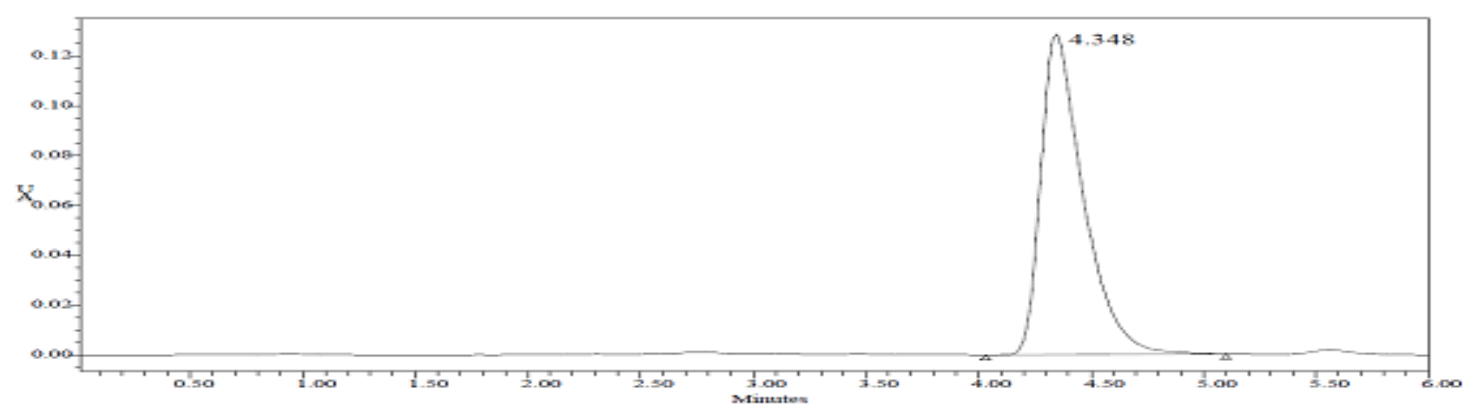

\begin{tabular}{|c|c|}
\hline $\begin{array}{c}\text { Retention Time } \\
(\mathrm{min})\end{array}$ & $\begin{array}{c}\text { Area } \\
\left(\mu \mathrm{V}^{*} \mathrm{sec}\right)\end{array}$ \\
\hline 4.348 & 1992433 \\
\hline
\end{tabular}

Precision study (1)

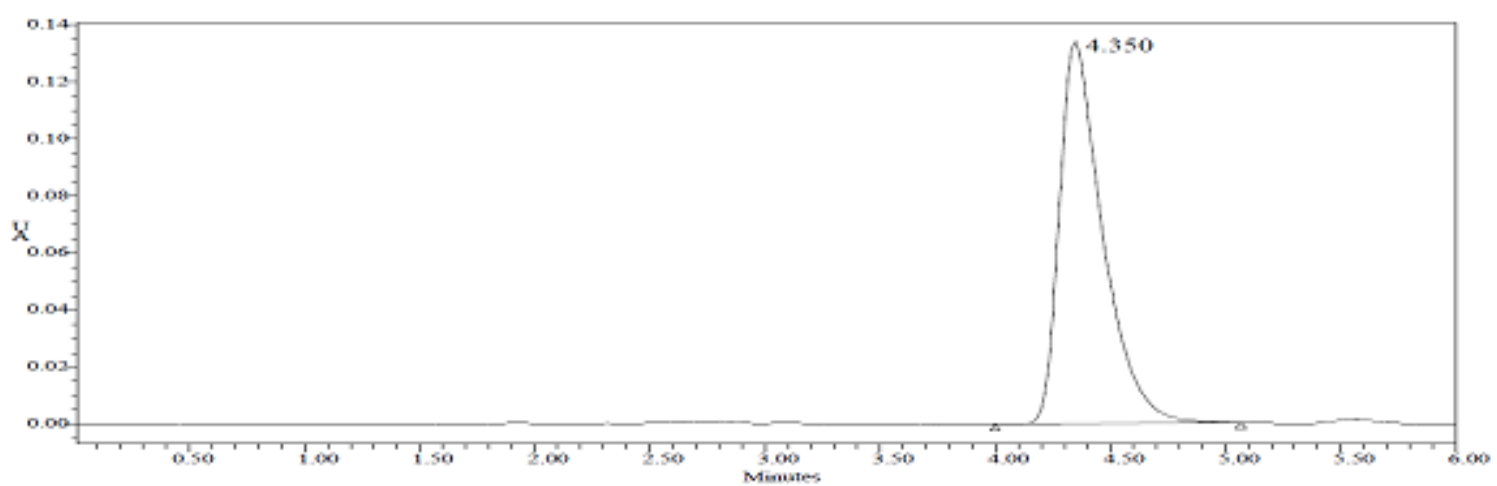

\begin{tabular}{|c|c|}
\hline $\begin{array}{c}\text { Retention Time } \\
(\mathrm{min})\end{array}$ & $\begin{array}{c}\text { Area } \\
\left(\mu \mathrm{V}^{*} \mathrm{sec}\right)\end{array}$ \\
\hline 4.350 & 1957712 \\
\hline
\end{tabular}

Precision study (2) 


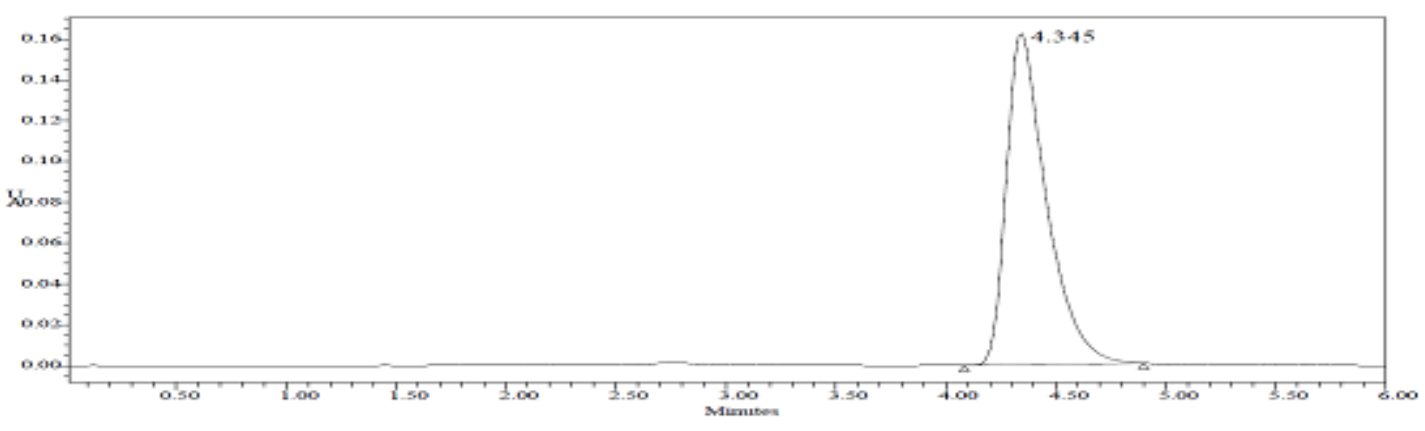

\begin{tabular}{|c|c|}
\hline $\begin{array}{c}\text { Retention Time } \\
(\mathrm{min})\end{array}$ & $\begin{array}{c}\text { Area } \\
\left(\mu \mathrm{V}^{*} \mathrm{sec}\right)\end{array}$ \\
\hline 4.345 & 1964881 \\
\hline
\end{tabular}

Precision study (3)

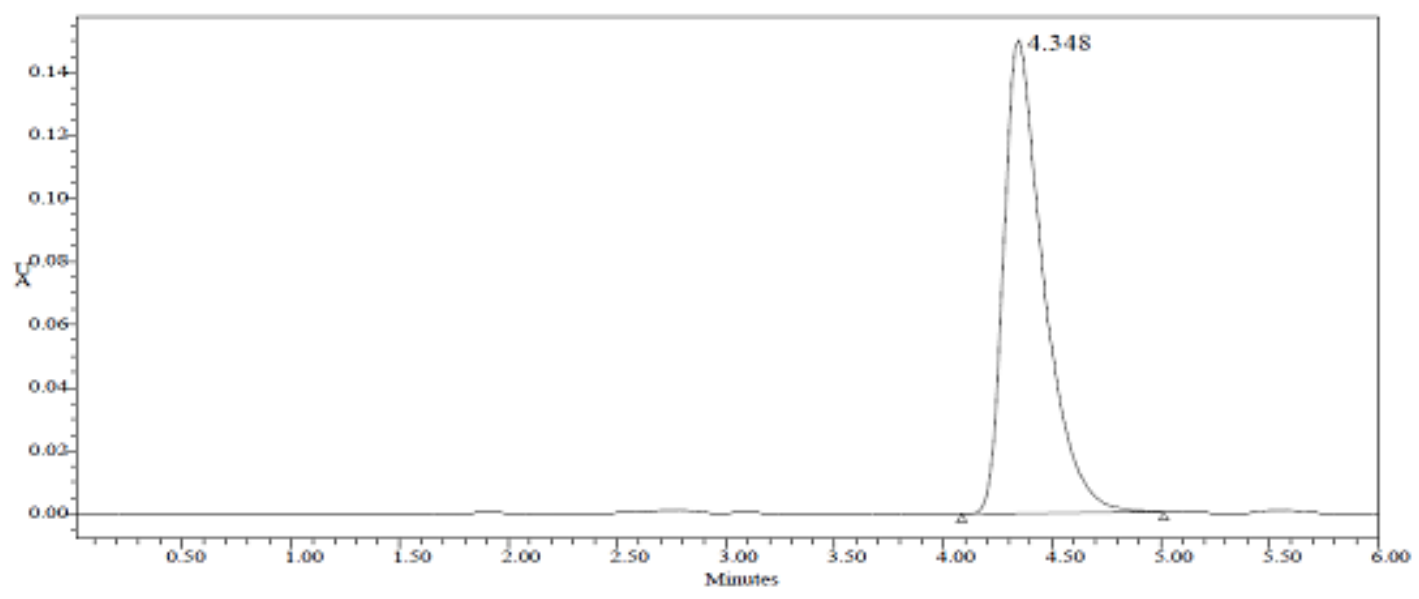

\begin{tabular}{|r|c|}
\hline $\begin{array}{c}\text { Retention Time } \\
(\mathrm{min})\end{array}$ & $\begin{array}{c}\text { Area } \\
\left(\mu \mathrm{V}^{*} \mathrm{sec}\right)\end{array}$ \\
\hline 4.348 & 1923517 \\
\hline
\end{tabular}

\section{Precision study (4)}

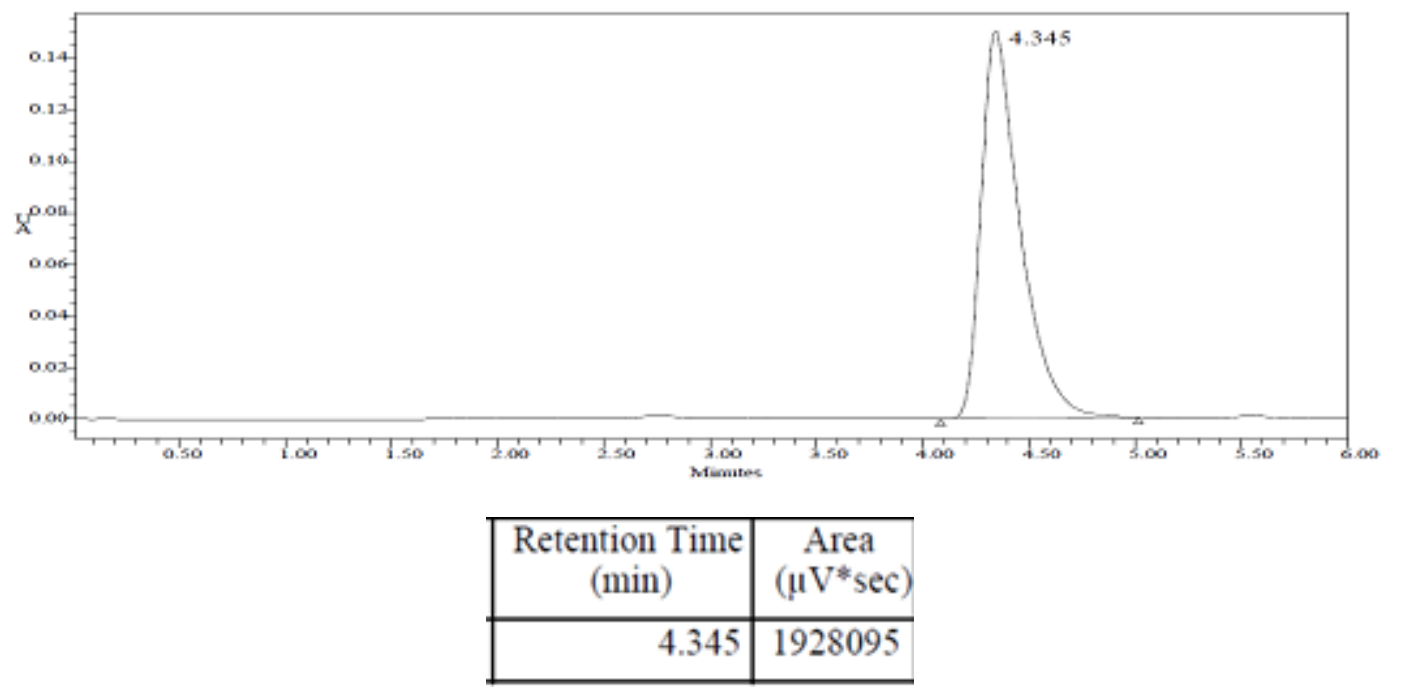

Precision study (5) 


\begin{tabular}{|c|c|c|c|c|}
\hline \multicolumn{2}{|c|}{ Precision Study Data } \\
\hline S.No & Peak Area & Average & SD & \% RSD \\
\hline 1 & 1992433 & & & \\
\hline 2 & 1957712 & & & \\
\hline 3 & 1964881 & & & \\
& & & & \\
\hline 4 & 1923517 & & & \\
\hline 5 & 1928095 & & & \\
\hline
\end{tabular}

$\%$ RSD value less than $2 \%$ was found

\section{Intermediate precision:}

Intermediate precision:

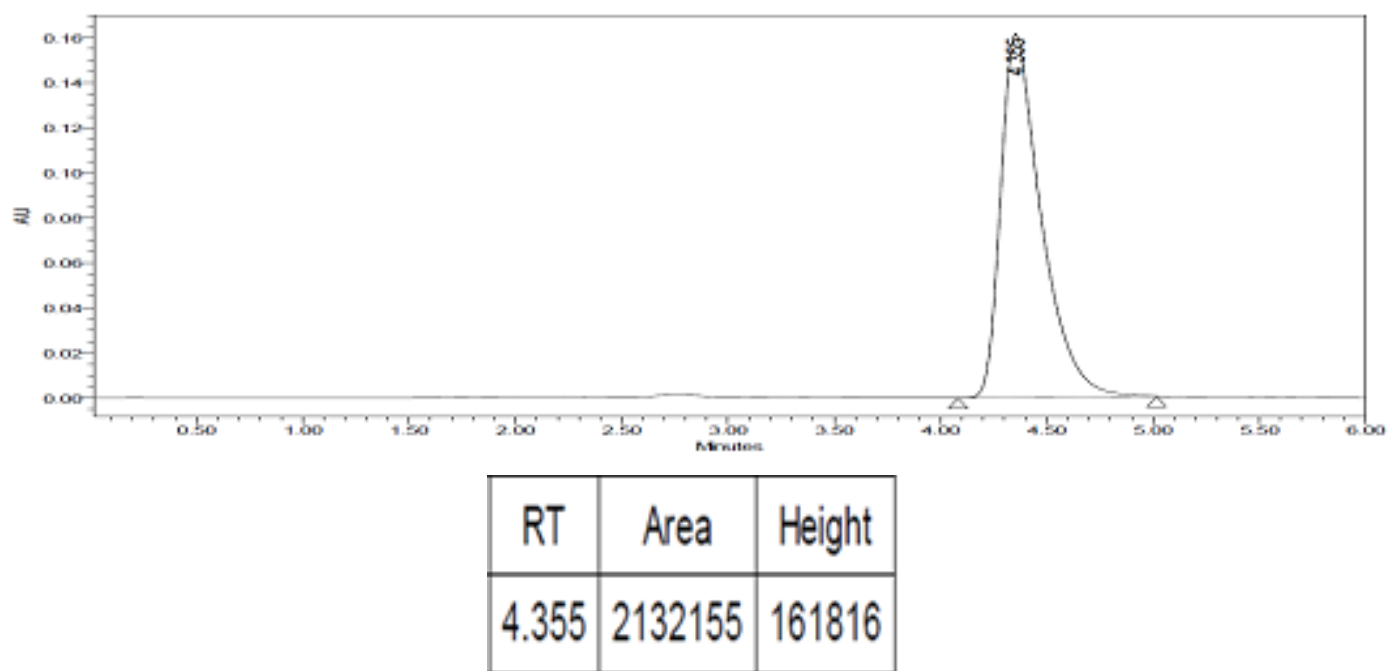

Intermediate precision Study (1)

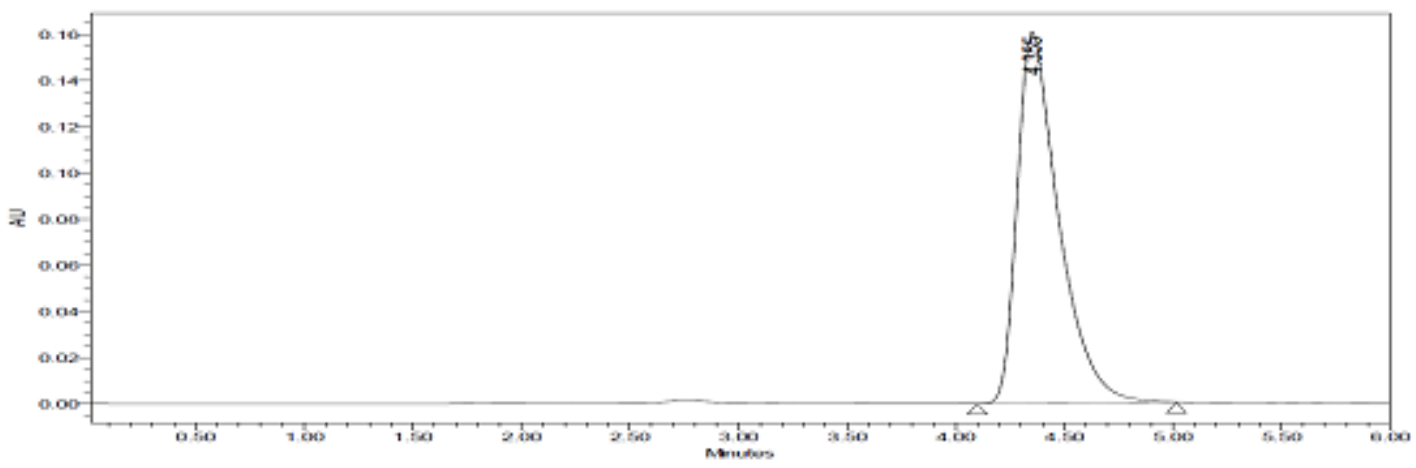




\begin{tabular}{|c|c|c|}
\hline RT & Area & Height \\
\hline 4.355 & 2133191 & 161179 \\
\hline
\end{tabular}

Intermediate precision Study (2)

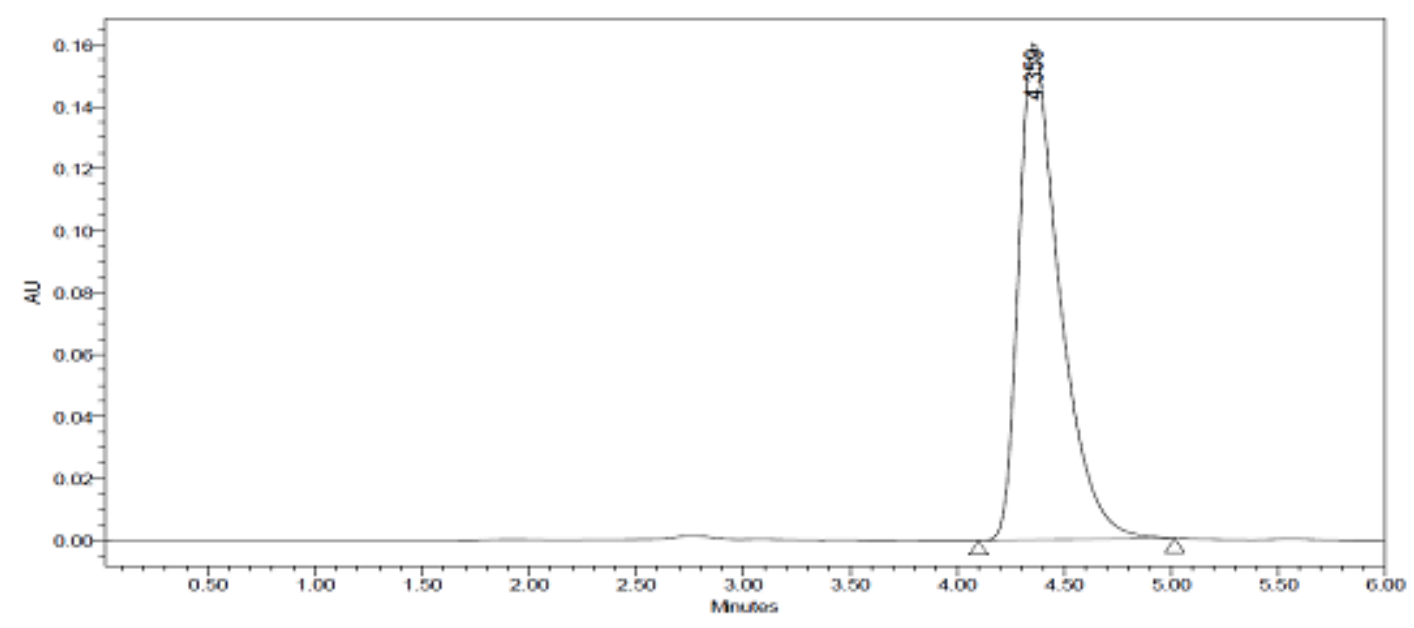

\begin{tabular}{|c|c|c|}
\hline RT & Area & Height \\
\hline 4.359 & 2127358 & 161047 \\
\hline
\end{tabular}

Intermediate precision Study (3)

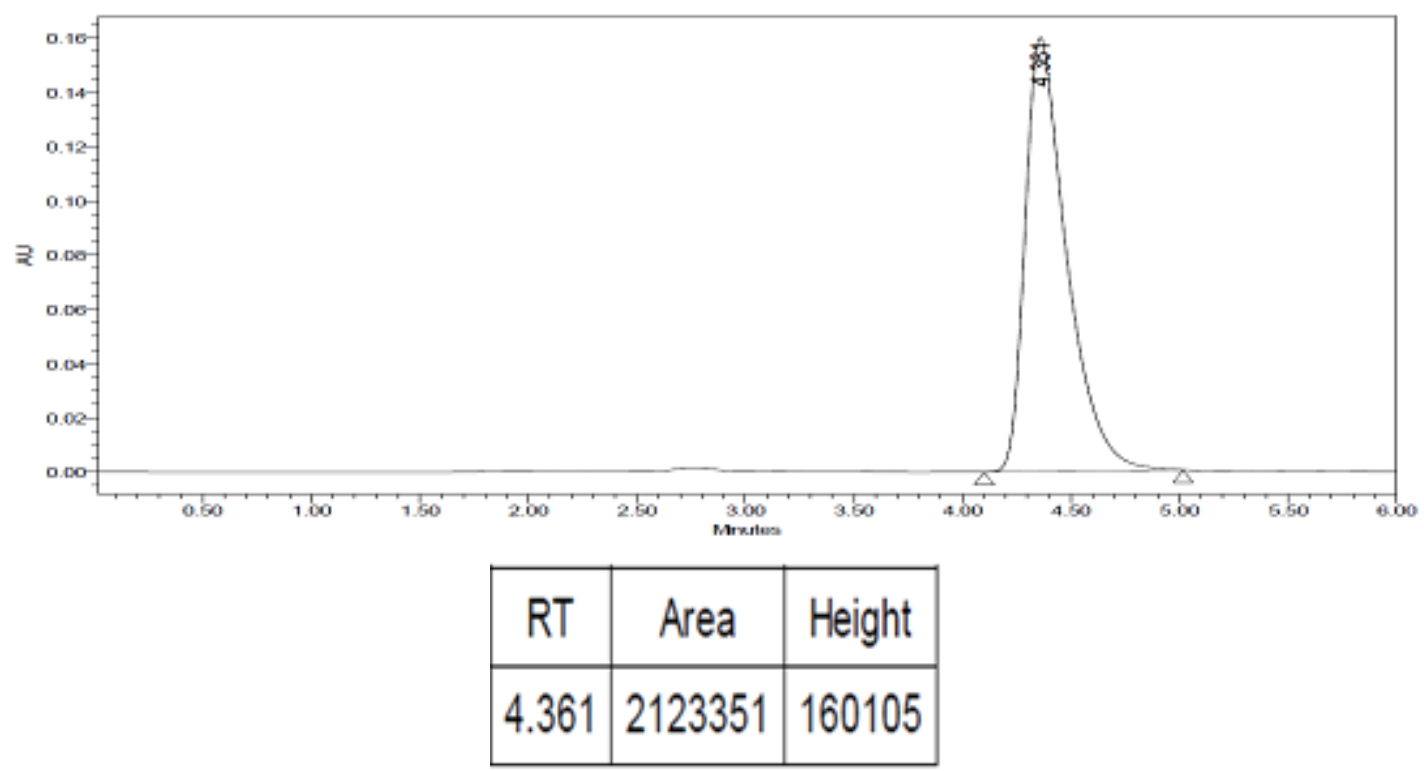

Intermediate precision Study (4) 


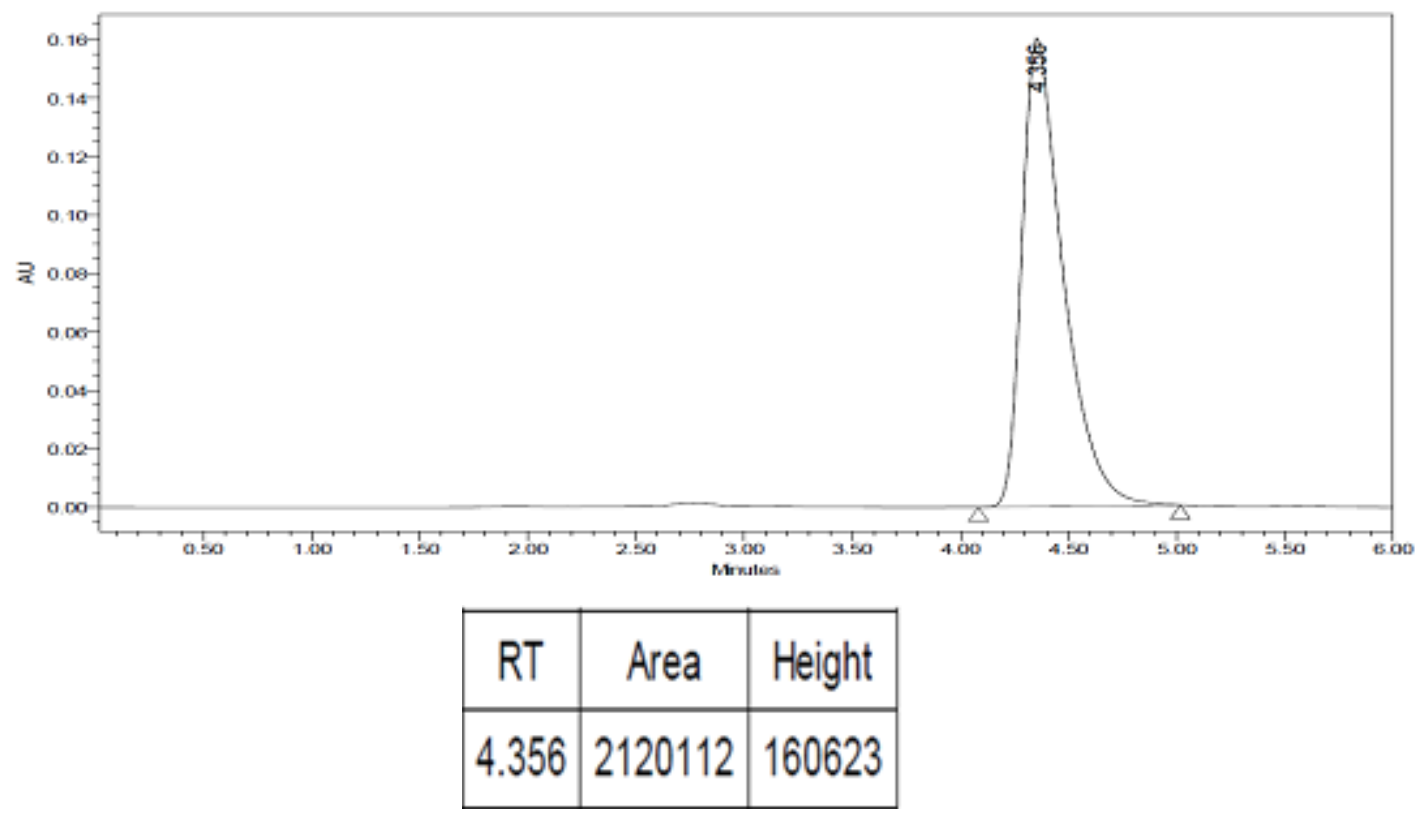

Intermediate precision Study (5)

Intermediate Precision

\begin{tabular}{|c|c|c|c|c|}
\hline S.No & Peak Area & Average & SD & $\%$ RSD \\
\hline 1 & 2132155 & \multirow{5}{*}{2127233} & \multirow{5}{*}{5601.7} & \multirow{5}{*}{0.26} \\
\hline 2 & 2133191 & & & \\
\hline 3 & 2127358 & & & \\
\hline 4 & 2123351 & & & \\
\hline 5 & 2120112 & & & \\
\hline
\end{tabular}

$\%$ RSD value less than $2 \%$ was found 


\section{Robustness}

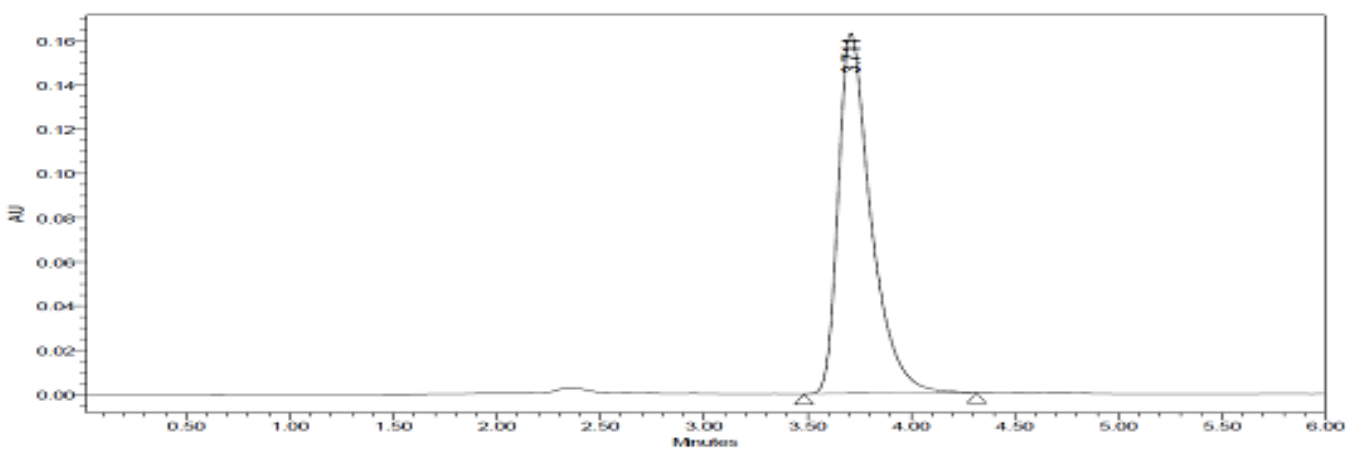

\begin{tabular}{|c|c|c|r|r|}
\hline RT & Area & Height & USP Plate Count & USP Taling \\
\hline 3.711 & 1789754 & 163567 & 2773.7 & 1.5 \\
\hline
\end{tabular}

Robustness -More flow

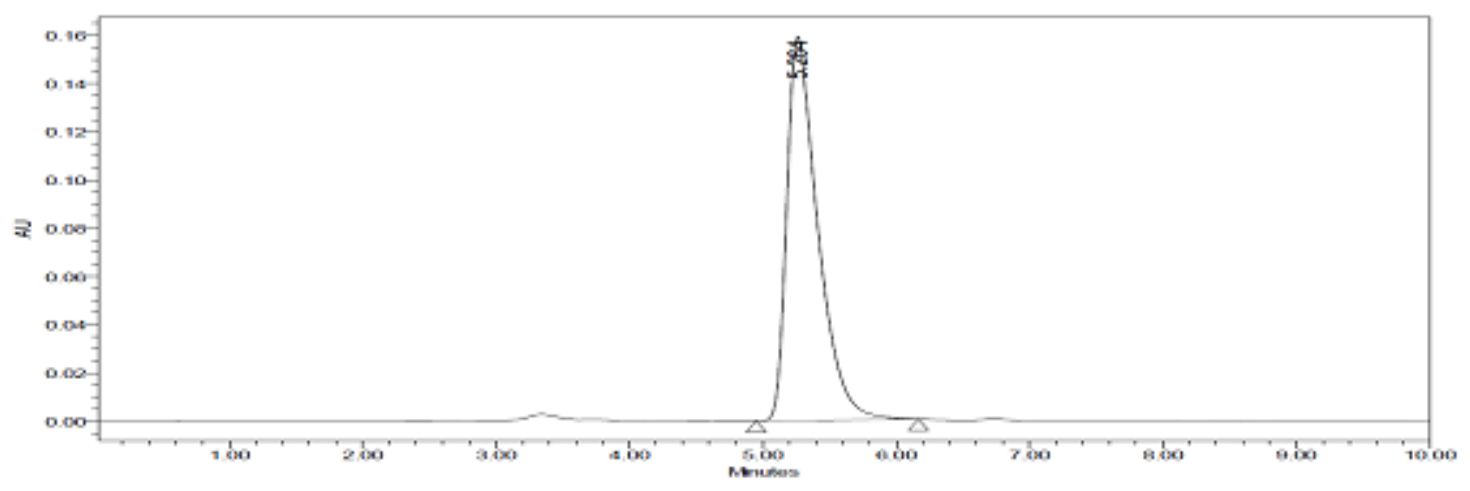

\begin{tabular}{|l|c|r|r|r|}
\hline RT & Area & Height & USP Plate Count & USP Taling \\
\hline 5.264 & 2564130 & 159352 & 2451.7 & 1.7 \\
\hline
\end{tabular}

Robustness -Less flow

Robustness - Flow Rate Variation data

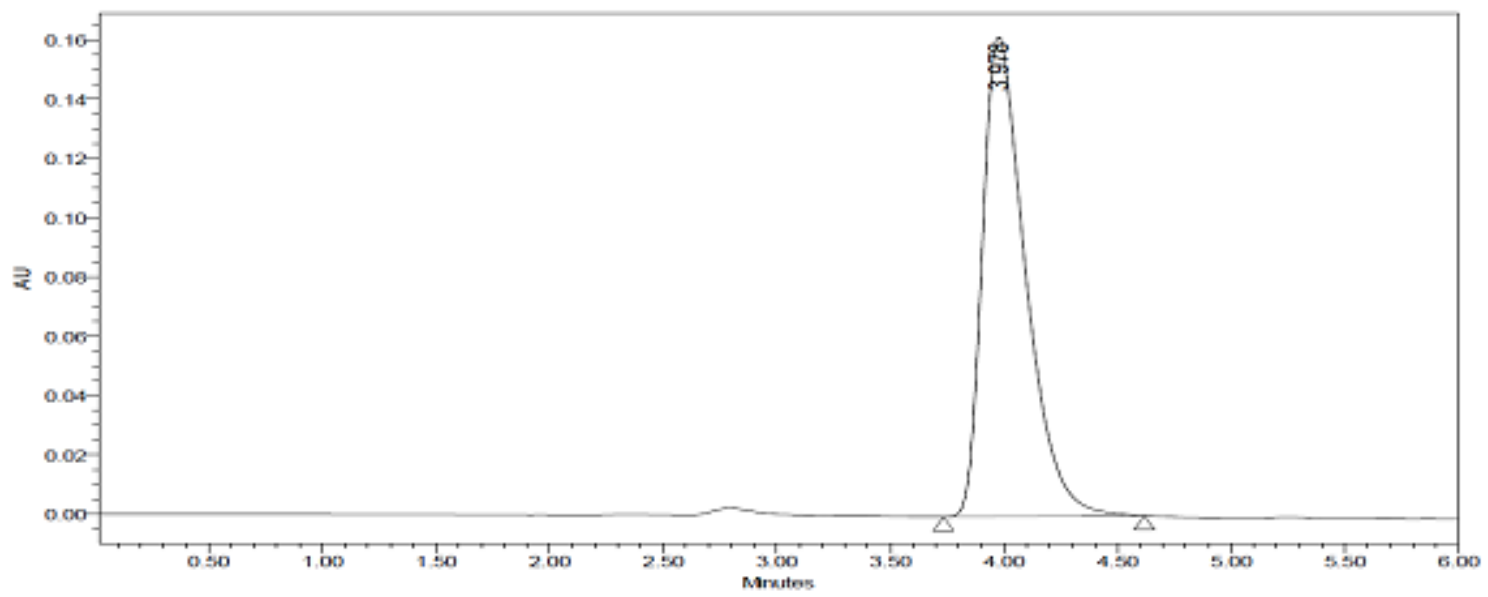




\begin{tabular}{|c|c|c|r|r|}
\hline RT & Area & Height & USP Plate Count & USP Taling \\
\hline 3.978 & 2128233 & 161853 & 2145.0 & 1.6 \\
\hline
\end{tabular}

\section{Robustness- More Organic}

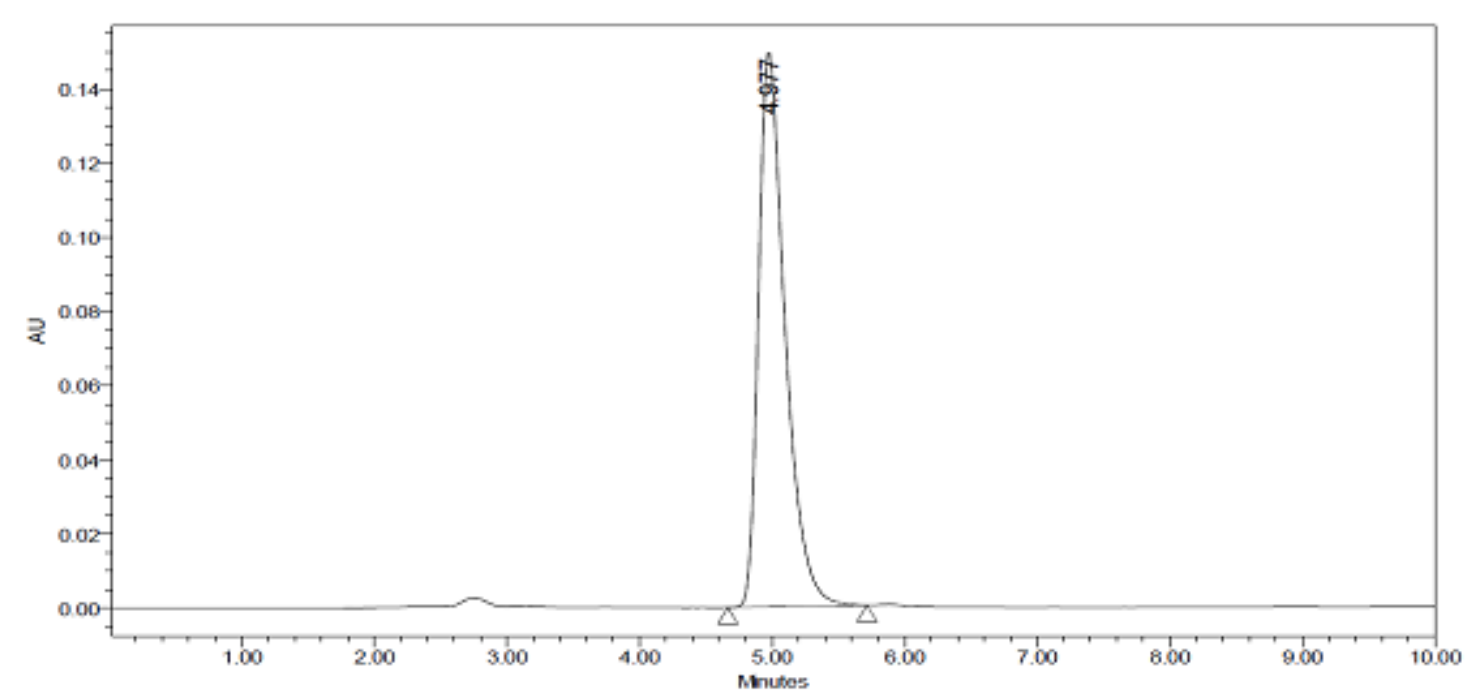

\begin{tabular}{|l|r|r|r|r|}
\hline RT & Area & Height & USP Plate Count & USP Taling \\
\hline 4.977 & 2092251 & 149696 & 2975.6 & 1.5 \\
\hline
\end{tabular}

Robustness- Less Organic

Robustness - Change in Organic Composition in Mobile Phase

\begin{tabular}{|c|c|c|c|}
\hline \multirow{2}{*}{ S.No } & Change in Organic & \multicolumn{2}{|c|}{ System Suitability Results } \\
\cline { 3 - 4 } S. & $\begin{array}{c}\text { Composition in the Mobile } \\
\text { Phase }\end{array}$ & USP Plate Count & USP Tailing \\
\hline 1 & $10 \%$ less & 2975 & 1.5 \\
\hline 2 & *Actual & 2669 & 1.6 \\
\hline 3 & $10 \%$ more & 2145 & 1.6 \\
\hline
\end{tabular}

\section{CONCLUSION}

In the present investigation, we have developed and validated simple, sensitive, precise and accurate RP HPLC method for the quantitative estimation of Capmatinib and pharmaceutical formulations. The results expressed in Tables and figures for HPLC method are promising. The HPLC method is more sensitive, precise and accurate compared to the spectrophotometric methods. This method can be used for the routine determination of Capmatinib in bulk drug and in Pharmaceutical formulations.

\section{ACKNOWLEDGMENT:}

I express my deep thanks and gratitude to my respectable, and beloved guide, our Principal, Vice principal, Nebulae Hi Tech Laboratory, Chennai - 116 and my Parents and friends for providing all the encouragement and facilities to complete my research work 
successfully. I would like to express my special thanks of gratitude to Tamilnadu Pharmaceutical Sciences Welfare Trust for having awarded third prize for this project.

\section{BIBLIOGRAPHY:}

1) https://en.wikipedia.org/wiki/Capmatinib

2) Wiley ICH Quality Guidelines: An Implementation Guide 2018 John \& Sons, Inc

3) Text book of instrumental method of chemical analysis 2018 Edition Gurdeep R. Chatwal Sham K. Anand:24-27

4) https://www.chemspider.com/Chemical-Structure.25069712.html

5) https://pubchem.ncbi.nlm.nih.gov/compound/25145656

6) Instrumental methods of analysis 2012 Edition Hobart H. Willard Merritt Dean Settle:583592.

7) https://go.drugbank.com/drugs/DB11791

8) Text book of pharmaceutical analysis, Forth edition, Dr. S. Ravi Sankar

9) High Performance Liquid Chromatography volume 1, P.D. Sethi. 